Document downloaded from:

http://hdl.handle.net/10251/123536

This paper must be cited as:

Bermúdez, V.; Luján, JM.; Climent, H.; Soto-Izquierdo, L.; Campos-Navarro, D. (2018). Analysis of Regulated Pollutant Emissions and Aftertreatment Efficiency in a GTDi Engine Using Different SOI Strategies. SAE International Journal of Engines. 11(3):363-382. https://doi.org/10.4271/03-11-03-0025

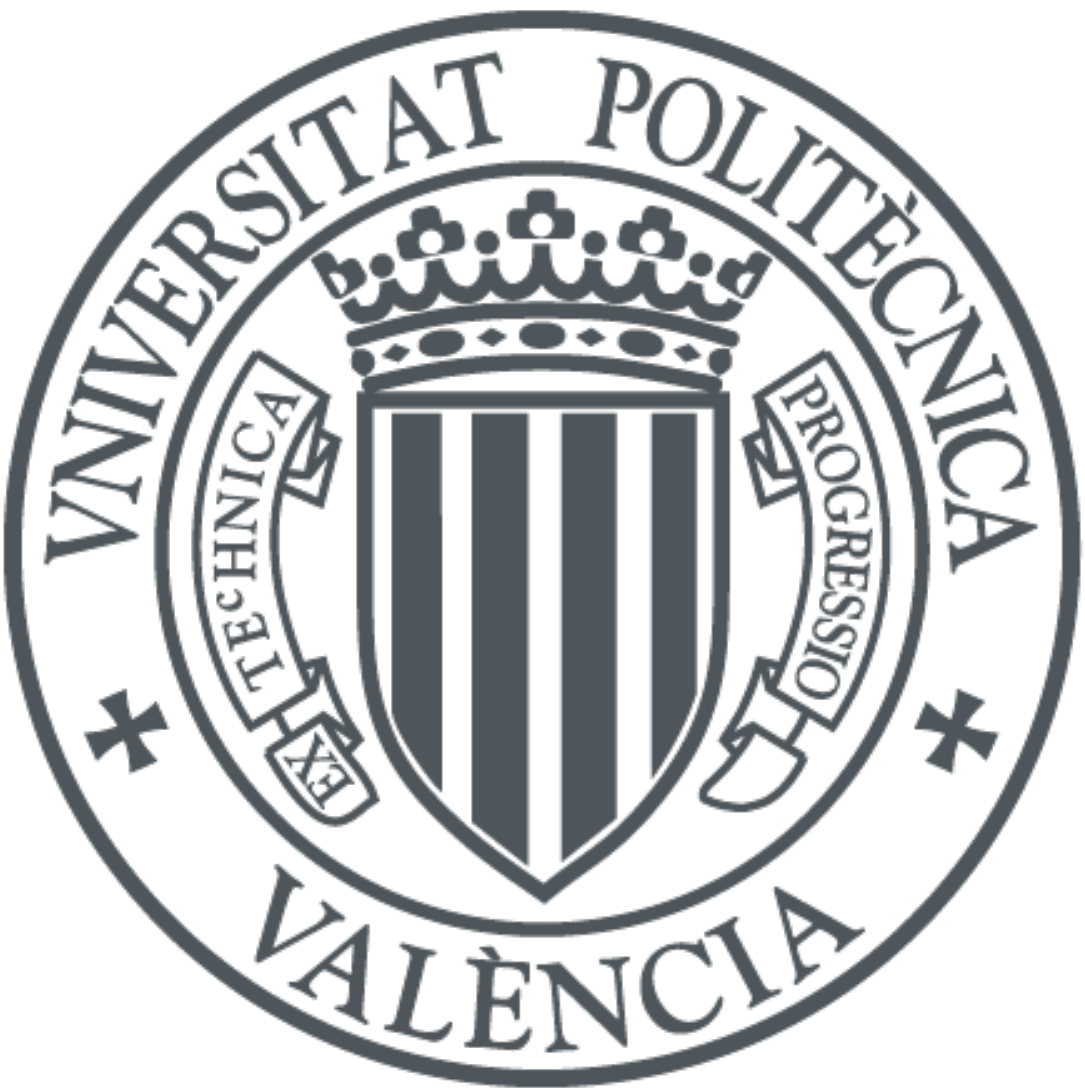

The final publication is available at

https://doi.org/10.4271/03-11-03-0025

Copyright SAE International

Additional Information 


\title{
Analysis of regulated pollutant emissions and aftertreatment efficiency in a GTDi engine using different SOI strategies.
}

\author{
Vicente Bermúdez ${ }^{\mathrm{a}}$, José Manuel Luján ${ }^{\mathrm{a}}$, Héctor Climent ${ }^{\mathrm{a}}$, Lian Soto ${ }^{\mathrm{a}}$ and Daniel Campos ${ }^{\mathrm{b}}$ \\ ${ }^{a}$ Universitat Politècnica de València, CMT-Motores Térmicos, Camino de Vera s/n, 46022 \\ Valencia, Spain. \\ ${ }^{\mathrm{b}}$ AVL List GmbH, Hans-List-Platz 1, 8020 Graz, Austria
}

\begin{abstract}
In order to improve performance and minimize pollutant emissions in gasoline turbocharged directinjection (GTDi) engines, different injection strategies and technologies are being investigated. The inclusion of exhaust gas recirculation (EGR) and the variation of the start of injection (SOI) are some of these strategies that can influence the air-to-fuel (AF) mixture formation and consequently in the combustion process and pollutant emissions. This paper presents a complete study of the engine performance, pollutant emissions and aftertreatment efficiency that produces the SOI variation with a fixed EGR rate in a 4-cylinder, turbocharged, gasoline direct-injection engine with $2.0 \mathrm{~L}$ displacement. The equipment used in this study are TSI-EEPS for particle measurement and HORIBA MEXA 1230-PM for soot measurement being HORIBA MEXA 7100-DEGR with a heated line selector the system employed for regulated gaseous emission measurement and aftertreatment evaluation. The experimental results confirm how the use of an adequate SOI strategy is indispensable to obtain low exhaust emissions values and a balance between the different pollutants. There was found a slight reduction in brake specific fuel consumption (BSFC) with the SOI advance. The experiments showed a decrease in $\mathrm{CO}$, a non-sensible variation of THC and an increase in NOx emissions with SOI delay. Additionally, a significant increase in particle emissions was observed with early SOIs. Finally, with the SOI delay the aftertreatment performance revealed an increase in the oxidation of $\mathrm{CO}$ and a decrease in the reduction of NOx.
\end{abstract}

\section{Keywords}

GTDi engine; SOI variation; engine performance, gaseous emission; soot emission; particle size distribution; TWC efficiency 


\section{Introduction}

Regarding environmental pollution, Internal Combustion Engine (ICE) emissions are known to represent a significant portion of air pollutants. This worsening of air quality, especially in large urban areas significantly affects both human health and the environment. In this sense, it has been shown that some cardiovascular and carcinogenic problems are also linked to particulate matter (PM) emissions, specifically ultrafine particles which, because of their size, can pass from the lungs into the bloodstream [1,2]. The total unburned hydrocarbons (THC) and nitrogen oxides (NOx) are precursors of ozone, a gaseous compound which, at ground level, can affect the airways and cause changes in lung function [3,4]. Another adverse effect of the NOx is the acid rain, which can disturb ecosystems and can cause biological death in lakes and rivers [5].

Due to increasing social awareness about human health and the environment, the regulations in charge of the limits for the emissions produced by ICEs have evolved significantly [6]. In this context, fuel consumption and the maximum limits of the more harmful pollutants (NOx, THC, carbon monoxide (CO) and PM) have drastically decreased over the last decade.

For improving fuel economy, turbocharged direct-injection gasoline (GTDi) engines are becoming the substitutes to the traditional port fuel injected (PFI) gasoline engines. The reduction in fuel consumption is mainly due to the improvements carried out in atomization and vaporization fuel process through high-pressure (up to 350 bar) injection systems, becoming highly popular in the world market since they are improving downsizing and power density [7]. On the one hand, the time available for fuel injection and complete fuel droplet evaporation is greatly reduced due to the direct injection into the cylinder, leaving unburned fuel on the cylinder wall and the piston surface. This causes an increase of THC and soot emissions [8]. On the other hand, the increase in power density in GTDi engines leads to higher temperatures in the combustion chamber, increasing the NOx emissions [9].

In general, spraying the fuel directly into the chamber lowers the temperature allowing higher compression ratios [10], which leads for a fuel consumption improvement. Those systems can be operated in stratified-combustion or homogeneous-combustion modes. During stratified-charge operation the fuel vaporizes as combustion occurs and the air-to-fuel (AF) ratio in the cylinder is not thoroughly mixed. This allows for reduced the fuel consumption at idle and low load conditions, along with the ability to run the engine un-throttled. In contrast, fuel-rich zones can facilitate the particle formation at high temperatures [11-13]. During homogeneous-charge operation, since fuel is 
sprayed directly into the chamber during the intake stroke there is no fuel inefficiency due to wall impingement and the fuel events can be further controlled with higher precision.

Until the introduction of Euro 5 legislation, the compliance of the pollutants emitted by GTDi engines had been achieved using three-way catalyst (TWC) systems, but the increase in particle emissions has led to the inclusion of a PN emissions limit in the Euro 6 legislation. In this sense, the implementation of the gasoline particle filter (GPFs) has become an alternative to reduce the particles number emitted by those engines. However, the fact of incorporating more and more aftertreatment systems in the exhaust system causes an increase in the back pressure and, therefore, an increase in the pumping losses, producing increases in fuel consumption $[14,15]$.

The function of the TWC is the simultaneous reduction of all gaseous compounds through a single element. For this purpose, the current systems are based on the catalytic properties of platinum group metals (PGM) such as platinum $(\mathrm{Pt})$, palladium $(\mathrm{Pd})$ and rhodium $(\mathrm{Rh})$ for the reduction and oxidation reactions $[16,17]$. The $\mathrm{CO}$ and $\mathrm{HC}$ abatement are mainly achieved through oxidation reactions with the remaining $\mathrm{O}_{2}$ in the exhaust gas; while the NOx reduction is achieved by reacting the HCs and the CO with the NO $[18,19]$. However, the operation of this aftertreatment system is highly conditioned by the AF ratio and exhaust gas temperatures (EGT) In this sense, at stoichiometric conditions and at high temperatures best efficiency for the TWC is achieved $[19,20]$.

Regarding PM emissions, soot is mainly formed from carbon, which originates from a high combustion temperature and occurs as an intermediate step between fuel evaporation and fuel dehydrogenation [21]. In diesel engines, where the fuel is injected during the compression stroke, the combustion process occurs with stratified charge. The combustion starts in the stoichiometric zones, where the heat released in these regions allows the spread of combustion in poor zones, while in the fuel-rich zones the combustion is controlled by slow diffusion flame [11]. The elevated temperatures in the fuel-rich zones are responsible for the soot formation. This principle opposes the combustion process that occurs in GDI engines. Ignition delay and early SOI (during the intake stroke) provide the more homogeneous charge reducing the fuel-rich zones, so the traditional soot formation mechanism may not be applied for GDI engines $[22,23]$.

The soot formation process in GDI engines has been extensively investigated in several studies [22,24-26]. These studies concluded that the soot formation can be attributed to different factors: (i) short time for AF mixture preparation due to a delayed SOI leading to rich local zones and, (ii) the fuel film trapped on the piston surface and the cylinder wall, which typically occurs when the SOI is carried out very early during the intake stroke, and (iii) injection characteristics such a spray cone 
angle, tip penetration and injector diffusion flame, and (iv) hardware interactions like impingement on the liner or spray interaction with the intake valves.

In this framework, to improve performance and minimize the emissions in GTDi engines, different strategies and technologies have been adopted, some of which are still being investigated, such as:

- The incorporation of exhaust gas recirculation (EGR) systems, which provides a reduction in the combustion temperature and consequently a reduction in NOx emissions [27,28]. The EGR also better facilitates TWC efficiency due to a more uniform mixture, especially during engine operation at low load $[9,29]$. In addition, EGR can replace fuel enrichment in gasoline engine to inhibit knock [9]. In general, the addition of EGR causes a dilution effect in the charge and consequently the combustion degradation, being necessary to maintain an appropriate phasing in the park-plug (SP) timing in order to produce the correct combustion process and reach the desired torque. Several authors have explored this effect, concluding that SP timing is increased as the EGR rate increases [30,31].

- The spray-guided technology for better control of the AF mixture formation and a complete combustion process. This technology uses the placement of the injector near the SP which carries a suitable mixture around it during the fuel injection event and spraying process [32]. This technique has shown better results than the wall-guided combustion mode, which increases the THC emissions, and the air-guided combustion mode which leads to poor control of the AF mixture $[33,34]$.

- Lastly, the variation of the start of injection (SOI) is also being investigated. A simple strategy that can greatly influence the combustion process and pollutants emissions. The SOI during the intake stroke facilitates the formation of homogenous charge, because the fuel evaporation time is long enough, but may be too poor for ignition at low a temperature and pressure. Contrarily, the SOI delay to the compression stroke generates a stratified charge, and the evaporation time is reduced providing fuel-rich zones [32].

Referring to the last aspect, different studies can be found in the bibliography. The experiments carried out by Li et al. [35] showed a considerable increase in $\mathrm{CO}$ emissions with the SOI delay in a GDI engine. With a stoichiometric $\mathrm{AF}$ ratio at $1800 \mathrm{rpm}$ engine speed, the $\mathrm{CO}$ emissions increase from about 20 to $100 \mathrm{~g} / \mathrm{kWh}$ for a SOI delay of 180 to 90 crank angle degree (CAD) before top dead center (BTDC) respectively. This result was linked to an increase in the charge stratification with the SOI delay. 
Price et al. [36] observed an increase in PM mass concentration over one order of magnitude with the SOI delay from 60 to $160 \mathrm{CAD}$ after top dead center (ATDC) in a spray-guided GDI engine with toluene as fuel. In that case, the reduction of the time for the AF mixture preparation was the responsible factor for the increase of particle mass concentration. The lower volatility of toluene compared to other fuels proved this behavior even more.

In a GDI engine, Bonatesta et al. [37] used an early SOI (315 CAD BTDC or earlier) for the enable better AF mixture preparation and maintain a brake mean effective pressure (BMEP) higher than 7 bar at high engine speed (> $3000 \mathrm{rpm}$ ). A significant increase in PN emissions was observed in the mentioned conditions. The authors justified a large part of this behavior with a fuel increase which is deposited in the piston surface provided by the SOI advance.

Finally, in the work of Zheng et al. [38] on a GDI engine it was identified that the SOI advance of 2nd injection event provided a more homogeneous AF mixture and better combustion, which in turn contributed to an increase in the EGT and, therefore, to a better efficiency of the catalytic converter.

According to the previous considerations, the main objective of this paper is to analyze experimentally the effects of the SOI variations on exhaust gas emissions behavior and TWC efficiency from a GTDi engine equipped with a low-pressure EGR (LP-EGR). In this sense, it is uncommon to find all these topics included in the same research paper, being this issue the main contribution of this work and not to optimize the engine used to fulfill any legislation. Two different steady-state homogeneous-combustion operating points in terms of engine speed and load were investigated; both at $50 \%$ of load but one at $2000 \mathrm{rpm}$ and the other at $3000 \mathrm{rpm}$. The equipment used in this study are TSI-EEPS for particle size distribution measurement and HORIBA MEXA 1230PM for soot measurement being HORIBA MEXA 7100-DEGR with a heated line selector the system employed for regulated gaseous emission measurement and aftertreatment evaluation. A specific test procedure was also developed to ensure that variations on the emissions were not due to different exhaust temperatures (enough stabilization time for each variation), leaving only the SOI variations as the single responsible factor for the pollutants variations. In this sense, also a detailed description about how to move from base calibration settings to the same operating point including EGR will be shown. 


\section{Material and Methods}

This section includes the main characteristics of the engine as well as the main properties of the fuel used. In addition, a detailed description of the different measurement systems used for pollutants emission measurement and the test methodology are given.

\section{Test bench facilities and fuel used}

In this study a Euro 5 GTDi engine with 4-cylinder and $2.0 \mathrm{~L}$ displacement including a serial TWC was used. This engine has a Bosch fuel injection system equipped with 4 injectors. Each one has seven holes nozzle and are placed between the intake valves with an inclination of $45^{\circ}$ with respect to the vertical axis of the cylinder, allowing a maximum injection pressure up to $15 \mathrm{MPa}$. Detailed specifications of the engine are given in Table 1.

Table 1. GTDi engine main characteristics.

\begin{tabular}{|l|l|l|}
\hline Characteristic & Unit & Value \\
\hline Type & - & 4-cycle \\
\hline Valves by cylinder & - & 4 \\
\hline Number of cylinders & - & 4 \\
\hline Compression ratio & - & $10.2: 1$ \\
\hline Diameter & $\mathrm{mm}$ & 87 \\
\hline Stroke & $\mathrm{mm}$ & 83 \\
\hline Maximum power & $\mathrm{kW}$ & 153 at $6000 \mathrm{~min}^{-1}$ \\
\hline Maximum torque & $\mathrm{Nm}$ & 300 at $2000 \mathrm{~min}^{-1}$ \\
\hline
\end{tabular}

A custom-made LP-EGR system was added since original engine did not include the EGR path. The exhaust gas was extracted downstream of the TWC and recirculated to the compressor inlet, allowing homogenous mixture (fresh air + EGR) at the intake manifold [39]. The LP-EGR line design was done incorporating a water-gas cooler which allowed control in EGR gas temperature, followed by a control valve which controlled EGR rate.

To make possible modifications in the SOI and SP timing, the engine control unit (ECU) was partially opened and the engine setting maps could be modified with the ETAS-INCA software.

The engine was installed in a fully instrumented test cell, with all the auxiliary facilities required for its operation and control. In this sense, it was connected to a dynamometric brake SCHENCK DYNAS3 LI250, which allows engine speed and torque control. The test bench was fully equipped with $\mathrm{K}$ thermocouples and mean pressure sensors in the exhaust, cooling, intake and lubricating paths. 
Fuel consumption was determined by an AVL-733S Dynamic Fuel Balance. The Sensyflow-P hotplate anemometer system was used to measure the air mass flow rate on the intake side. In this regard, the characteristics and the error of the instrumentation of the sensors are summarized in Table 2.

Table 2. Characteristics of engine instrumentation.

\begin{tabular}{|l|l|l|l|}
\hline Magnitude & Sensor/instrument & Range & Error \\
\hline Temperature & Thermocouple Type K & {$[-200-1200]^{\circ} \mathrm{C}$} & $\pm 1.1^{\circ} \mathrm{C}$ or $0.4 \%$ (actual value) \\
\hline Mean Pressure & Piezoresistive PMA P40 & {$[0-6] \mathrm{bar}$} & $\pm 0.3 \%$ (full scale) \\
\hline Fuel mass flow & Gravimetric balance AVL-733S & {$[0-27] \mathrm{kg} / \mathrm{h}$} & $\pm 0.12 \%$ (full scale) \\
\hline Air mass flow & Sensyflow ABB FMT700-P & {$[0-720] \mathrm{kg} / \mathrm{h}$} & $\pm 1 \%$ (actual value) \\
\hline Torque & Torquimeter & {$[-650-650] \mathrm{N} . \mathrm{m}$} & $\pm 0.1 \%$ (full scale) \\
\hline
\end{tabular}

A commercial gasoline (which fulfills the Directive(EU) 2016/802 legislation [40] for European market) with a research octane number (RON) of 98 was used in all the tests performed. The specifications of the fuel properties are provided in Table 3.

Table 3. Gasoline properties.

\begin{tabular}{|l|l|l|}
\hline Property & Unit & Value \\
\hline RON & - & 98 \\
\hline Density at $15{ }^{\circ} \mathrm{C}$ & $\mathrm{kg} / \mathrm{m}^{3}$ & 735.7 \\
\hline Lower heating value & $\mathrm{MJ} / \mathrm{kg}$ & 44.09 \\
\hline Sulfur content & $\mathrm{ppm}$ & 7.3 \\
\hline Oxygen & $\mathrm{wt} \%$ & 2 \\
\hline Aromatic hydrocarbons & $\mathrm{Vol} \%$ & 22.9 \\
\hline Benzene & $\mathrm{Vol} \%$ & 0.68 \\
\hline Distillation $\mathrm{T} 10 \%$ Vol. & ${ }^{\circ} \mathrm{C}$ & 51.3 \\
\hline Distillation $\mathrm{T} 50 \% \mathrm{Vol}$. & ${ }^{\circ} \mathrm{C}$ & 85.8 \\
\hline Distillation $\mathrm{T} 90 \% \mathrm{Vol}$. & ${ }^{\circ} \mathrm{C}$ & 142.9 \\
\hline
\end{tabular}

\section{Experimental Set-up}

As shown in Figure 1, three different exhaust gas analyzers were used in this study for pollutants emission measurement. 


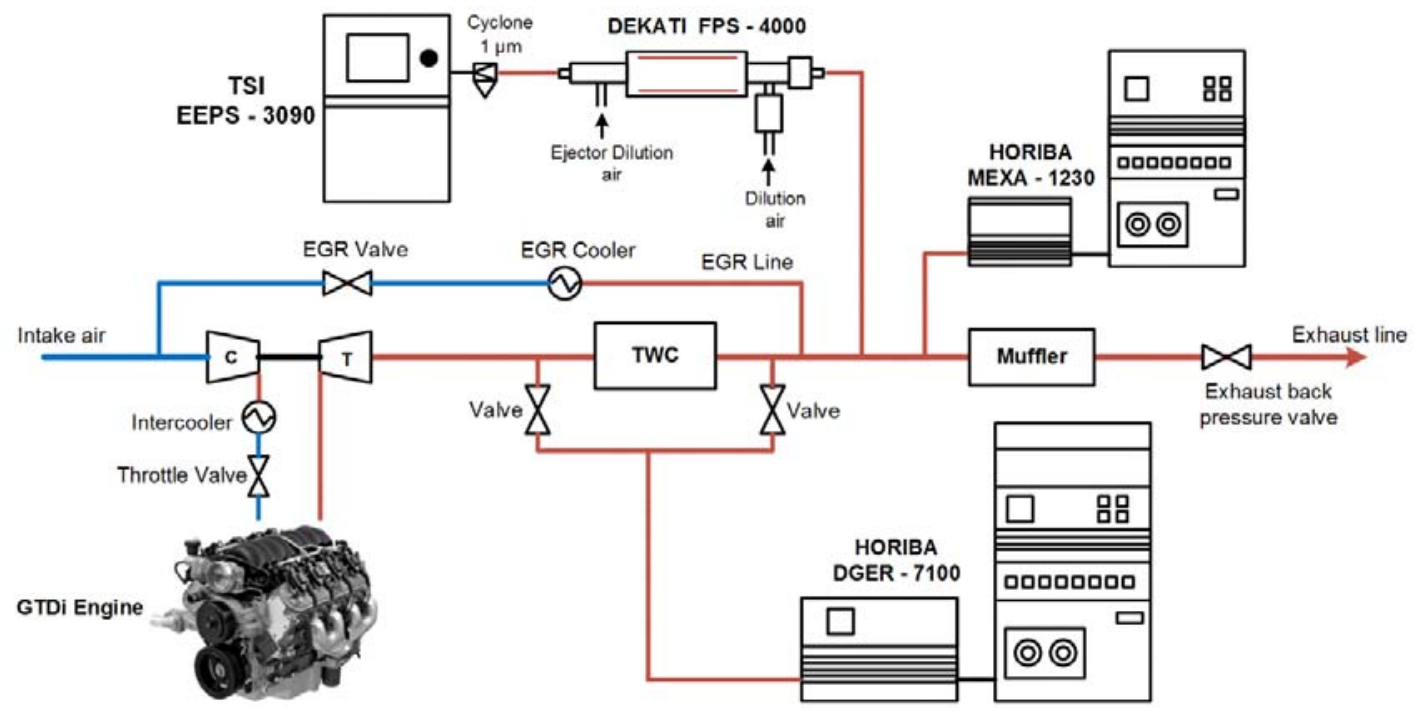

Figure 1. Experimental set-up for pollutants emissions evaluation in a GTDi engine.

For regulated gaseous compounds measurement, an HORIBA MEXA 7100D-EGR was installed to provide both raw and tailpipe emissions and EGR ratio through the carbon dioxide $\left(\mathrm{CO}_{2}\right)$ measurements. To establish a quantification of the efficiency of the aftertreatment device, a heated valve system concept was installed to assess the TWC efficiency during the steady-state operating points.

An HORIBA MEXA 1230-PM which includes a TSI-DCS100 was used to provide the soot emission rate. The system consists of a diffusion charging sensor (DCS) with a specific dilution device for soot measurement [41]. The dilution ratio used for the sample preconditioning was defined according to Bermúdez et al.[42].

A two-stage dilution system Dekati Fine Particle Sampler (DEKATI-FPS 4000) was coupled with a TSI Engine Exhaust Particle Sizer (TSI-EEPS 3090) to determine the particle size distribution (PSD). TSI-EEPS 3090 is capable for measuring PSD with a frequency up to $1 \mathrm{~Hz}$ providing a measurement range between 5.6 and $560 \mathrm{~nm}$.

\section{Particle measurement method}

The dilution system used in this study dilutes the exhaust sample in two stages. In the first isothermal porous tube diluter (PTD) the concentration of the volatile is reduced and stabilize avoiding nucleation preventing the formation of new nano-particles (A to B way in Figure 2). The ejector diluter (ED) acts as a secondary diluter (B to $\mathrm{C}$ way in Figure 2) reducing both temperature and particle concentration. 


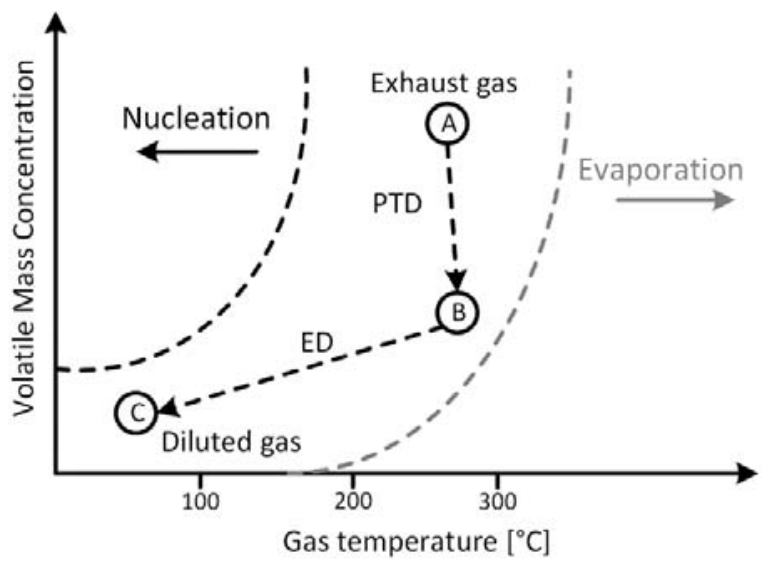

Figure 2. Particle evolution at dilution system. Theoretical phase-diagram used in the methodology for measuring particle size distribution [46].

The dilution ratio and dilution air temperature affect the gas-to-particle conversion in the measurements. A significant reduction of both parameters can increase the phenomena of nucleation and adsorption/condensation of volatiles. In this sense, an increase in the total concentration of nucleation-mode particles could occur under these conditions since these particles are constituted mainly by volatile condensed material. Additionally, the size of the accumulation-mode particles could increase due to the absorption of volatile condensates on their surface [43-45]

To reduce the problems mentioned above and considering that the same dilution system is used to dilute the exhaust gases, the measurement methodology described by Desantes et al. [46] was applied in this study, as shown in Figure 2. Such measurement procedure was developed to reduce the sensitivity of particle size measurements due to different dilution settings. In this sense, the dilution ratio used in this study was 30 and the dilution air temperature was $220^{\circ} \mathrm{C}$.

\section{Calculations method}

During the test performed, the brake specific fuel consumption (BSFC) was determined by measuring fuel mass flow and the mechanical power $(\mathrm{Pe})$ taking into account the effective torque and engine speed.

$B F S C=\frac{\dot{m}_{f u e l}}{P_{e}}$

The EGR rate was calculated from $\mathrm{CO}_{2}$ concentrations taken at the intake and exhaust manifolds. Equation 1 defines the calculated EGR rate as: 
$E G R=\frac{\mathrm{CO}_{2, \text { int }}-\mathrm{CO}_{2, \mathrm{~atm}}}{\mathrm{CO}_{2, \text { exh }}-\mathrm{CO}_{2, \mathrm{~atm}}} \cdot 100$

In Equation 2, $\mathrm{CO}_{2, \text { int }}$ is the Vol.\% of $\mathrm{CO}_{2}$ measured at the intake manifold being $\mathrm{CO}_{2 \text {,ext }}$ the Vol.\% of $\mathrm{CO}_{2}$ taken at exhaust manifold. Atmospheric carbon dioxide was considered as $\mathrm{CO}_{2, \text { atm. }}$.

The method adopted for conversion efficiency calculation was based on Equation 3.

$T W C_{e f f}=100-\frac{X_{\text {down }}}{X_{u p}} \cdot 100$

In Equation 3, $\mathrm{X}_{\text {down }}$ and $\mathrm{X}_{\text {up }}$ are each gaseous pollutant concentration downstream and upstream the TWC respectively.

Regarding particle concentration measurement, PSD may be decomposed by Equation 4 according to Seinfeld et al.[47]. It establishes that total particle size distribution is the sum of two particle mode concentrations (nucleation-mode and accumulation-mode), assuming the log-normal size distribution function:

$\frac{d N_{i}}{d \log d p_{i}}=\frac{1-x}{\sqrt{2 \pi} \log \sigma_{g 1}} \cdot e^{-\frac{\log ^{2}\left(\frac{d p_{1}}{d p_{g 1}}\right)}{2 \log ^{2} \sigma_{g 1}}}+\frac{1-x}{\sqrt{2 \pi} \log \sigma_{g 2}} \cdot e^{-\frac{\log ^{2}\left(\frac{d p_{2}}{d p_{g}}\right)}{2 \log ^{2} \sigma_{g 2}}}$

The nucleation-mode represents the particles with sizes lower than $50 \mathrm{~nm}$ in diameter, although some authors define this limit as $30 \mathrm{~nm}$. Some authors state that particles belonging to this mode are mainly formed by volatile components such as unburned hydrocarbon and sulfates $[48,49]$, but also some others state that nucleation mode are the main precursors for soot particles and the composition can be carbonaceous substances derived from the pyrolysis reaction [50,51]. The other mode is the accumulation-mode, which is formed for particles between $30 \mathrm{~nm}$ to $1 \mu \mathrm{m}$ and its chemical composition is of agglomerates of soot with hydrocarbons absorbed on the surface $[22,52,53]$.

In Equation $4, x$ is the ratio of the total particle concentration concentrations of two distributions, $d_{p 1}$, $\mathrm{d}_{\mathrm{p} 2}, \mathrm{~d}_{\mathrm{pg} 1}, \mathrm{~d}_{\mathrm{pg} 2}, \sigma_{1}$ and $\sigma_{2}$ are the geometric mean diameters, median diameters, and geometric standard deviations of each peak, and $\mathrm{N}_{\mathrm{i}}$ is the particle concentration of particle size $\mathrm{d}_{\mathrm{pi}}$. In this study, the decomposition of particle size distribution is nucleation-mode particles from 5.6 to $30 \mathrm{~nm}$; and accumulation-mode particles from 30 to $560 \mathrm{~nm}$.

To calculate total particle number concentration $(\mathrm{dN})$ the Equation 5 is used for each mode: 
$d N=\sum_{d p(\text { lower })}^{d p(\text { upper })} d N_{i}$

All measurements made with TSI-EEPS 3090 were scaled properly with the dilution ratio in order to bring the particle concentration to the raw emission on measurement position.

\section{Results variability analysis}

The variability and significance of the measurement were calculated through StatGraphics software. In the following paragraphs the sequence to obtain means representative values and their deviation is descripted.

For each day and each measurement, mean values and its coefficient of variation (COV) of raw data collected were firstly calculated.

$\bar{X}_{d a y, 1} \pm \operatorname{COV}_{\text {day }, 1}$

$\bar{X}_{d a y, 2} \pm \operatorname{COV}_{d a y, 2}$

$\bar{X}_{d a y, 3} \pm \operatorname{COV}_{\text {day }, 3}$

The Equation 6 show the total mean value (TMV), calculated as a mean of the three means of each day, being this value the one represented on the graphs.

$T M V=\frac{\bar{X}_{d a y, 1}+\bar{X}_{d a y, 2}+\bar{X}_{\text {day }, 3}}{3}$

The maximum and minimum variation of each TMV was adopted calculating the maximum or minimum variation of the three COVs calculated. Equation 8 and 9 represent those calculations.

$$
\begin{aligned}
& \operatorname{Max}_{v a r}=\operatorname{Maximum}\left(\bar{X}_{d a y, 1}+\operatorname{COV}_{d a y, 1} ; \bar{X}_{d a y, 2}+\operatorname{COV}_{d a y, 2} ; \bar{X}_{d a y, 3}+\operatorname{COV}_{d a y, 3}\right)-T M V \\
& \operatorname{Min}_{v a r}=T M V-\operatorname{Minimum}\left(\bar{X}_{d a y, 1}-\operatorname{COV}_{d a y, 1} ; \bar{X}_{d a y, 2}-\operatorname{COV}_{d a y, 2} ; \bar{X}_{d a y, 3}-\operatorname{COV}_{d a y, 3}\right)
\end{aligned}
$$

Thus, the points showed at each plot are:

$T M V \pm_{\text {Min }_{\text {var }}}^{\text {Max }_{\text {var }}}$

\section{Test schedule}

Two different steady-state operation points were chosen for the experiments performed, being both at $50 \%$ load but one at $2000 \mathrm{rpm}$ and the other at $3000 \mathrm{rpm}$. In those operation points, a homogeneous- 
charge combustion strategy was used since the injection event was carried out during the intake stroke, allowing enough time to homogenize the air-fuel mixture. The reference SOI for 2000rpm_50\% operating point was 280 CAD BTDC being the studied SOIs 260, 270, 290 and 300 CAD BTDC. The reference SOI for 3000rpm_50\% operating point was 290 CAD BTDC being the SOIs analyzed 270, 280, 300 and 310 CAD BTDC. The main parameters of each operating point studied are shown in Table 4.

The reference operating points and the influence of the EGR rate inclusion on this engine was analyzed by Bermúdez et al. [9] and Luján et al. [54]. The basis of the previous investigation was focused to find the maximum EGR rate allowed at iso-torque experiments. Thus, once the EGR rate was analyzed previously, the focus of this paper to bring knowledge about the influence of the SOI variation on pollutant emissions with a fixed EGR rate.

Table 4. Steady-state operating points and main parameters.

\begin{tabular}{|l|l|l|l|l|l|}
\hline Point & Speed & Torque & EGR & SP & SOI \\
\hline & [rpm] & {$[\mathbf{N m}]$} & {$[\mathbf{\%}]$} & ['BTDC] & ['BTDC] \\
\hline 2000_50SOI-20 & & & 17.5 & 33 & 260 \\
\hline 2000_50SOI-10 & & & 17.5 & 33 & 270 \\
\hline 2000_50SOI_Ref & $\mathbf{2 0 0 0}$ & $\mathbf{1 6 4}$ & $\mathbf{1 7 . 5}$ & $\mathbf{3 3}$ & $\mathbf{2 8 0}$ \\
\hline 2000_50SOI+10 & & & 17.5 & 33 & 290 \\
\hline 2000_50SOI+20 & & & 17.5 & 33 & 300 \\
\hline 3000_50SOI-20 & & & 17.5 & 42.5 & 270 \\
\hline 3000_50SOI-10 & & & 17.5 & 42.5 & 280 \\
\hline 3000_50SOI_Ref & $\mathbf{3 0 0 0}$ & $\mathbf{1 7 0}$ & $\mathbf{1 7 . 5}$ & $\mathbf{4 2 . 5}$ & $\mathbf{2 9 0}$ \\
\hline 3000_50SOI+10 & & & 17.5 & 42.5 & 300 \\
\hline 3000_50SOI+20 & & & 17.5 & 42.5 & 310 \\
\hline
\end{tabular}

In order to give a clear picture about how it is defined each variation of the SOI for both operating point, Figure 3 shows how the different SOIs are represented in the following graphs.

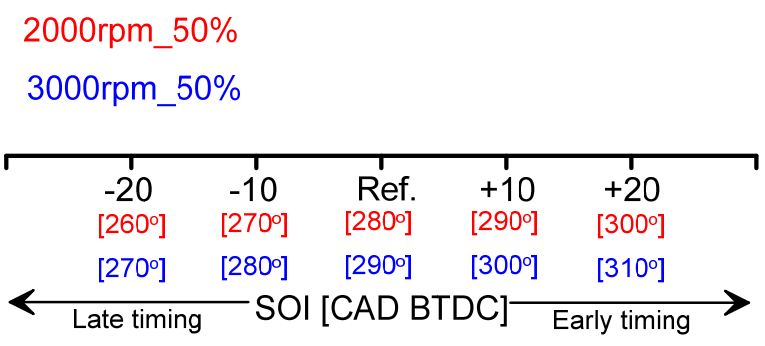

Figure 3. Indication of SOI variation. 


\section{Methodology test}

This section explains how the different parameters that control the combustion process were defined and stabilized for each operating point. It is important to note that the procedure carried out leads to the fact that base calibration needs to be enhanced if EGR is used since the reference engine operation is modified. The diagram in Figure 4 shows the methodology carried out:

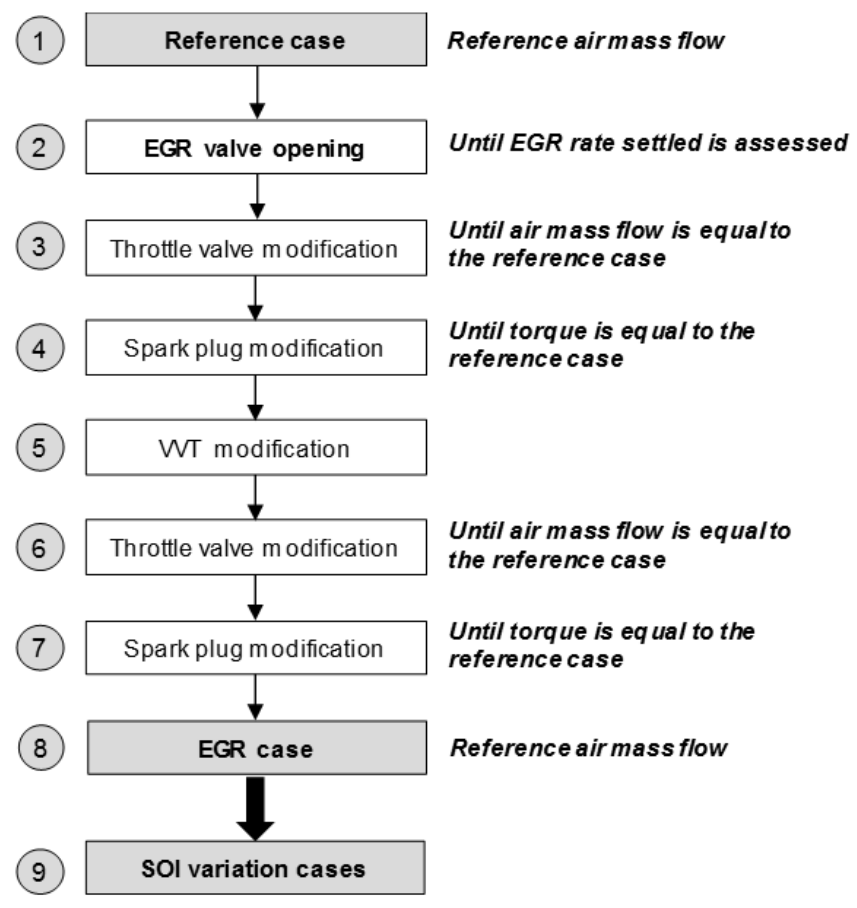

Figure 4. Methodology for setting the parameters that define the reference point.

- Initially the engine was operated in the reference operation point (without EGR) - Point 1 of the diagram.

- The EGR valve was progressively opened until the desired EGR rate was reached-Point 2 of the diagram.

- Since the addition of EGR causes a decrease in air mass flow rate and consequently deterioration in combustion process, the intake throttle valve was progressively opened until the same air mass flow rate than in the reference case was reached - Point 3 of the diagram.

- The new composition of the gas inside the cylinder caused a misalignment in the combustion process. Therefore, the SP timing was adjusted to reach the reference torque - Point 4 of the diagram. 
- The addition of EGR allows the reduction of trapped exhaust gases during valve overlap (VO) (in normal operating the $\mathrm{VO}$ allows to reduce the oxygen inside the cylinder, providing a less reactive charge and reducing the possibility of knocking). This procedure was carried out by modifying the variable valve timing (VVT) to reduce the VO. The results are shown in Figure 5 - Point 5 of the diagram.

- Since the modification of the VO also influenced intake air mass flow, the throttle valve was progressively opened again to reach the air mass flow measured in the reference case- Point 6 of the diagram.

- $\quad$ The procedure carried out in point 4 was repeated - Point 7 of the diagram.

- Once the same conditions as the reference case were reached (air mass flow), the SOI was varied without modifying any other parameter - Point 8 and 9 of the diagram.
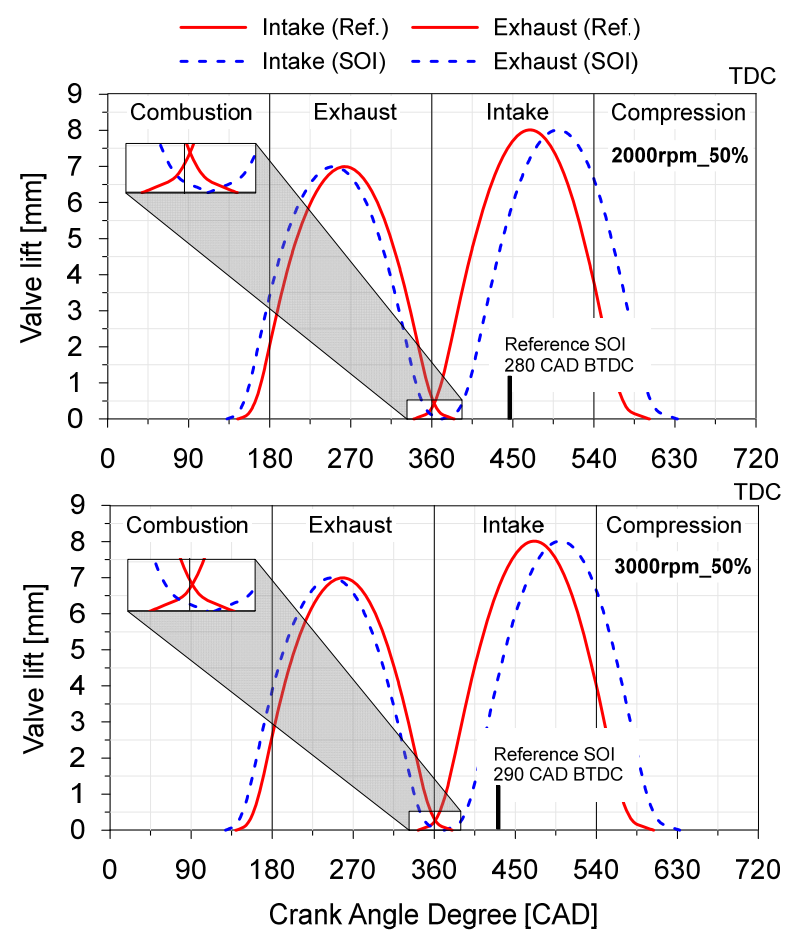

Figure 5. Modification in VVT to reduce the VO at each operating point.

\section{Methodology for testing steady-state operating points}

In order to test different SOIs at each engine speed, the methodology shown in Figure 6 was employed. This methodology was used to minimize the test-to-test variations: 
- The engine was run at reference steady-state operating point (engine speed, torque, EGR and SOI - Table 4). The time until the measurements were performed was determined by the variation at TWC outlet temperature. In this sense, when this temperature was stable, the measurements were carried out during two minutes at $1 \mathrm{~Hz}$.

- After that, the first SOI variation was assessed adding $10 \mathrm{CAD}$ to the reference SOI.

- The rest of the SOIs were performed in the same way that the first SOI.

- When the last SOI was assessed, the engine was taken to reference steady-state again, and the second reference operating point was measured.

To obtain representative results and improve their interpretation, the methodology described above was repeated for three different days. This procedure allowed data to generate results variability analysis from measurements and to obtain the mean value and deviation of each variable through the method described in Results variability analysis section.

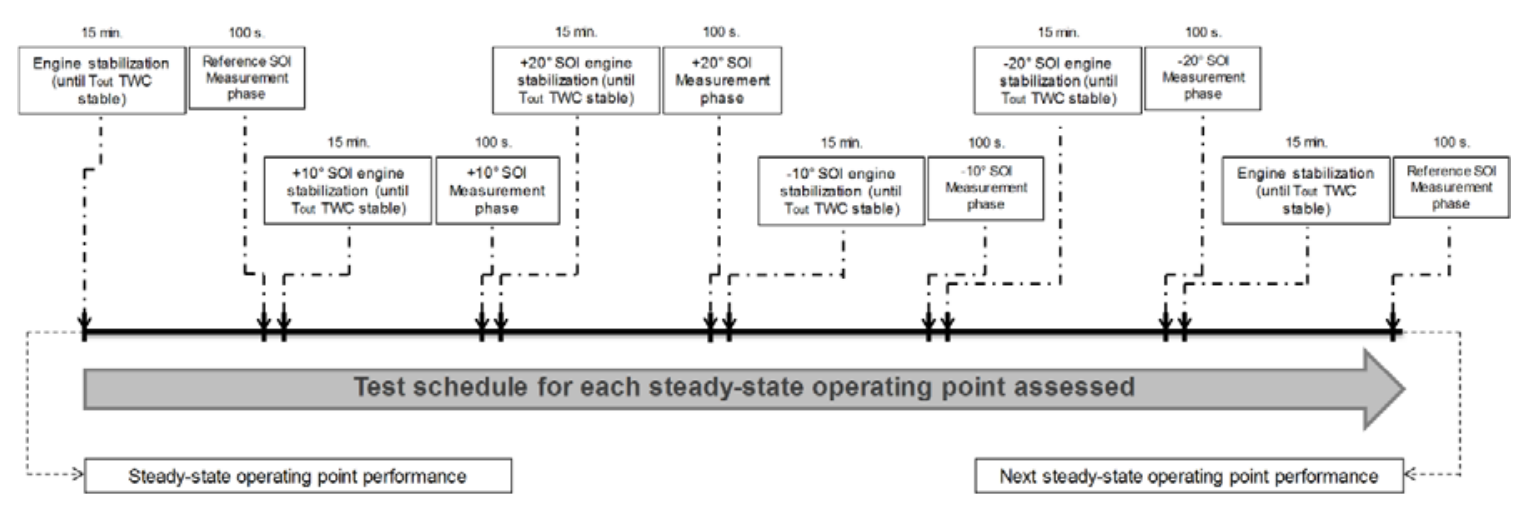

Figure 6. Methodology employed for testing each SOI at different steady-state operating points.

\section{Results and Discussion}

The analysis of the results has been divided into engine performance, gaseous emission, particle emissions and aftertreatment efficiency.

\section{Engine performance analysis}

To carry out an adequate parametric study of the SOI variation, it is important to maintain constant the following parameters: air mass flow, fuel mass flow, SP timing and EGR rate. Alterations in the values of the mentioned parameters can directly affect the combustion process and consequently the engine performance [55] and therefore the SOI variation would not be the only one responsible for 
the alterations in the pollutant emissions. Prior to this situation, as it shown in Figures 7A and 7B, air mass flow and fuel mass flow values were kept constant in all tests for each operating point.

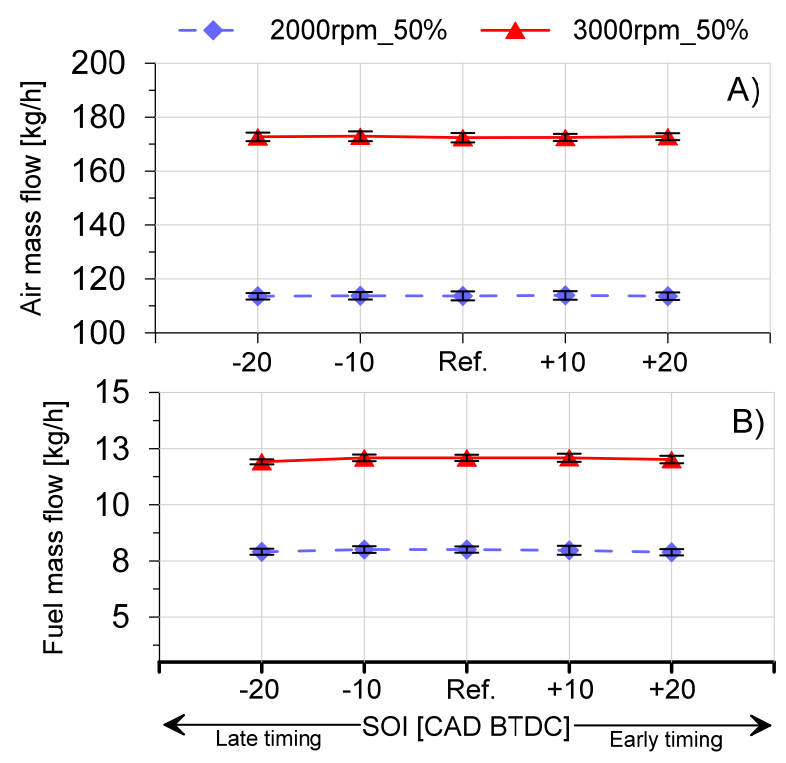

Figure 7. Air mass flow and fuel mass flow as function of SOI at each operating point.

Although the main purpose of this work is not to evaluate the use of different SOIs in terms of engine performance, the analysis of the BSFC trend for each variation is important in order to identify whether the SOI variations are really viable in each operation point. As it is shown in Figure 8A,a slight increase in the BSFC with early SOIs was observed.

On the one hand, since the SP timing was held constant, the rise of combustion pressure take place later which leads into losing efficiency and performance. If the SP timing is not shifted in order to center the combustion, the piston probably will be moving down in the expansion stroke when part of the combustion takes place (later SOI, late combustion). In this case the ability to expand this portion of the gas through the full range is lost, decreasing performance and increasing the BSFC.

On the other hand, the distance between the SOI and the piston position decreases with the late timings. The impact of the fuel on the piston can be much greater and eventually there will be an increase in the fuel film that is deposited on the piston surface and between the rings and combustion chamber walls $[36,56]$. Thus, part of the fuel trapped will not participate in the combustion process and then it cannot burn properly, which directly is reflected in the engine performance. 


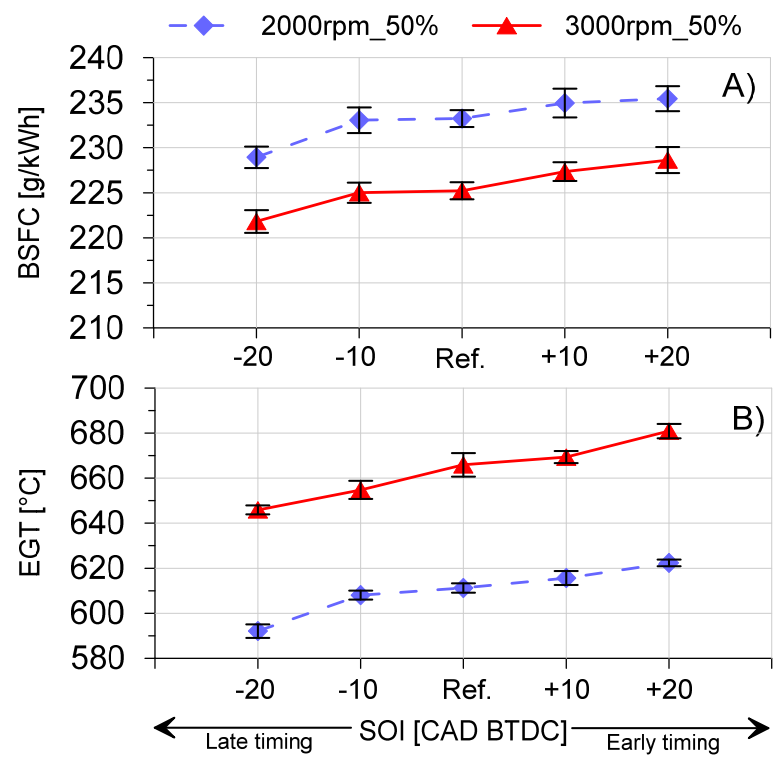

Figure 8. Engine performance for different SOIs at each operating point. (A) BSFC. (B) EGT.

Additionally, the Figure 8B illustrates the EGT measured in the exhaust manifold just before the inlet of the turbine. As it is shown, there is a slight increase in the temperature values in both operating points with the SOI advances. EGT represents the exhaust enthalpy of the gas for ideal gases which is a function of temperature and the combustion energy converted into expansion work. EGT also decreases if energy is conserved. In this sense, it is also related with the fact that ignition timing was keep constant and therefore a late timing will lead into a late combustion producing higher combustion temperatures.

\section{Gaseous emission analysis}

Concerning gaseous emission results, the analysis has been divided into the different compounds: raw THC, raw CO and raw NOx emissions.

\section{Raw THC emission analysis}

Figure 9A shows the raw THC emissions for the different SOIs. As a general remark, the raw THC emissions show few variations in both operating points (2000rpm_50\% and 3000rpm_50\%).

In 2000rpm_50\% operating point there was a slight decrease of $14 \%$ in raw THC emissions as the SOI was advanced [from $2.31 \mathrm{~g} / \mathrm{kWh}$ for latest SOI (260 CAD BTDC) to $2.03 \mathrm{~g} / \mathrm{kWh}$ for the earliest SOI (300 CAD BTDC)]. Late SOIs cause a reduction in the time for the preparation of the AF mixture, which can promote a decrease in the degree of evaporation of the fuel and a decrease in the homogenization of the charge, producing an increase in THC emissions. Additionally, since the 
injectors are placed between the intake valves, a change in the injection timing can lead to a valve impingement, which produces an increase in the THC [57,58]. In this sense, the later the SOI the higher intake valve lift as it is observed in Figure 5.

In 3000rpm_50\% operating point, the trend observed was slightly different than the one showed by $2000 \mathrm{rpm} \_50 \%$. In this case, the raw THC emissions stay almost in a constant value (approximately $1.90 \mathrm{~g} / \mathrm{kWh}$ ), as it shown in Figure 9A. This behavior could be due to a higher speed of the piston, which leads to a reduction in the time to prepare the AF mixture and an increase of flow velocities and therefore an increase in the turbulence.
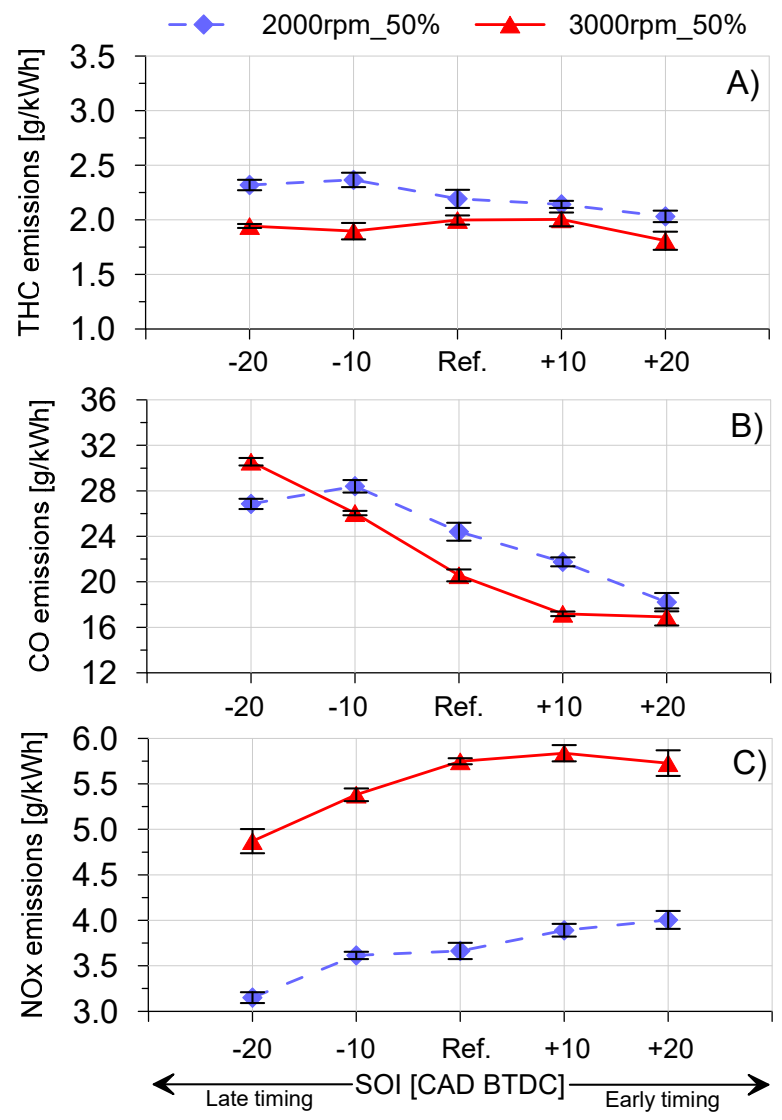

Figure 9. Gaseous emission for different SOIs at each operating point. (A) Raw THC emission. (B) Raw CO emission. (C) Raw NOx emission.

In the present study the engine hardware was kept the same and only the injection timing was varied, therefore variations in THC due to oil leakage and blow-by were not considered. Contrarily, wall impingement and $\mathrm{AF}$ mixture preparation time are the mainly drivers for the THC change. In that case, during the rich-combustion operation (i.e. lambda $<1$ ) the lack of oxygen and the low temperatures in the combustion chamber provide an incomplete combustion process, which directly 
affects the secondary hydrocarbons oxidation reactions in the expansion and exhaust strokes. However, in the test carried out, the global AF ratio remained constant for both operating points and for the different SOIs. This is mainly due to the dependence between THC emissions and the AF ratio, where the THC emissions increase with the mixture enrichment $[24,59]$.

\section{Raw CO emission analysis.}

Regarding the raw $\mathrm{CO}$ emissions, SOI variation has a strong influence on this compound than in the THC emissions, as it is shown in Figure 9B.

A considerable increase in raw $\mathrm{CO}$ emissions in both operating points with the SOI delay was observed. The emissions of the most advanced SOI were compared with those of the most delayed SOI in both operating points. In 2000rpm_50\% operating point there was an increase around $47 \%$ (18.20 to $26.85 \mathrm{~g} / \mathrm{kWh}$ ), and in 3000rpm_50\% operating point this increase was $81 \%$ (16.90 to 30.56 $\mathrm{g} / \mathrm{kWh})$.

The $\mathrm{CO}$ is formed mainly as the product of the incomplete combustion process in fuel-rich zones of the combustion chamber where air is insufficient being during expansion and exhaust strokes [60]. Two hypotheses are related with the increase on the $\mathrm{CO}$ with late timings. First the shorter time available for the AF mixture preparation, especially when the SOI is delayed, can lead to a inhomogeneous charge that increases fuel-rich zones and consequently produce higher $\mathrm{CO}$ emissions, as it is depicted in Figure 9B. Secondly, the steep increase in CO, linked to the reduction in EGT and BSFC could indicate an change in the combustion duration according to [61].

\section{Raw NOx emission analysis.}

The NOx are produced by the reaction between nitrogen and oxygen during the combustion process at high temperatures. Normally NOx are formed through high temperature oxidation of the diatomic nitrogen in combustion air. In general, it has been assumed that in the fuel rich zone little NOx will be formed because there is little available oxygen and that flame temperatures are relatively low [62]. Other factors that also have great influence on the NOx formation are the residence time for the reaction and also the oxygen concentration [63,64].

Figure 9C shows a reduction in raw NOx emissions with the SOI delay in both operating points. In 2000rpm_50\% operating point the NOx emissions decreased by $11 \%$ [from $4.01 \mathrm{~g} / \mathrm{kWh}$ for the most advanced SOI (300 CAD BTDC) to $3.55 \mathrm{~g} / \mathrm{kWh}$ for the most delayed SOI (260 CAD BTDC)]. In 
3000rpm_50\% operating point the NOx emissions decreased by $15 \%$ [from $5.72 \mathrm{~g} / \mathrm{kWh}$ for the most advanced SOI (310 CAD BTDC) to $4.87 \mathrm{~g} / \mathrm{kWh}$ for the most delayed SOI (270 CAD BTDC)].

The reduction of the raw NOx emissions can be related to the reduction in combustion temperature. Although there was no indicated measurement system to quantify thermodynamics inside the cylinder, the reduction in temperature combustion is proved by the EGT, as Figure $9 \mathrm{C}$ depicts. The decrease of combustion temperature is due to a degradation in the combustion process, that is a consequence of a deterioration in the synchronization between the time available for the AF mixture preparation and the SP timing. Previous works, presented by Costa et al. [65] and Sjöberg et al. [66] carried out these measurements and obtained similar results.

\section{Particulate Matter emissions}

Once the result in terms of gaseous compounds has been analyzed, the influence of SOI variation on soot and PN emissions is be analyzed in this section.

\section{Soot emission analysis}

Figure 10 shows the soot emissions for the different SOIs. At 3000rpm_50\% operating point there was an increase in soot emissions of $17 \%$ [from $0.94 \mathrm{~g} / \mathrm{kWh}$ for the reference SOI (290 CAD BTDC) to $1.20 \mathrm{~g} / \mathrm{kWh}$ for the most advanced SOI (310 CAD BTDC)]. Similar trend was observed in the $2000 \mathrm{rpm} \_50 \%$ operating point, even though the differences in soot emissions were higher. In this case, the increase was up to $140 \%$ [from $0.89 \mathrm{~g} / \mathrm{kWh}$ for reference SOI (280 CAD BTDC) to 2.15 $\mathrm{g} / \mathrm{kWh}$ for the most advanced SOI (300 CAD BTDC)]. This behavior can be due to the increase of the fuel film on the piston surface that provides the SOI advance and consequently an increase in the pool fire intensity. Another hypothesis can be related to the injector diffusion flame according to Berndorfer et al [26] where it was found that a detailed optimization of the relevant injector tip parameters controlling the atomization as well as the fuel injector tip interaction is necessary to lower the particulate number emissions in SI engines.

During the 2000rpm_50\% operating point, the highest value of soot emission was measured in the most advanced SOI (300 CAD BTDC). This value was higher than the value shown in the most advanced SOI (310 CAD BTDC) in the 3000rpm_50\% operating point. These results could be due to the fact that lower piston speed causes a longer interaction time between the non-evaporated fuel droplets and the piston surface. 


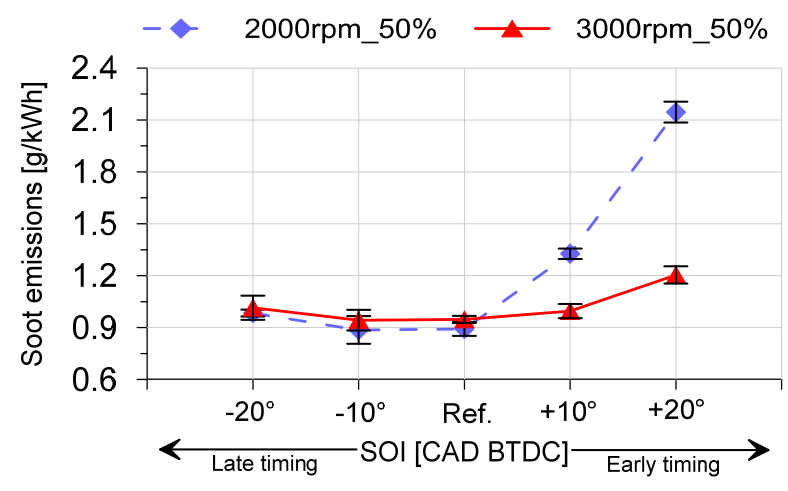

Figure 10. Soot emission for different SOIs at each operating point.

Finally, in both operating points different results in soot emissions was observed when the SOI was delayed from the reference SOI. In this case, soot emissions did not have significant variations; obtaining a few increases with the SOI delay. The increase in soot emissions was $10 \%$ for 2000rpm_50\% operating point [from $0.89 \mathrm{~g} / \mathrm{kWh}$ for the reference SOI to $0.98 \mathrm{~g} / \mathrm{kWh}$ for the most delayed SOI (260 CAD BTDC)] and 7\% for the 3000rpm_50\% operating point [from $0.94 \mathrm{~g} / \mathrm{kWh}$ for the reference SOI to $1.01 \mathrm{~g} / \mathrm{kWh}$ for the most delayed SOI (270 CAD BTDC)]. These results could demonstrate that for these SOIs the fuel film does not influence the soot emissions. In this case, the time reduction for the AF mixture preparation led to less time to mix and evaporate the fuel droplets, generating locally fuel-rich zones and incomplete combustion, factor that directly affects soot emissions.

\section{PN emission analysis.}

Figures 11A and 11B shows the PSDs at different SOIs for each operating point. In general, a bimodal structure was observed in both operating points. For the nucleation-mode, particles of less than 30 $\mathrm{nm}$ and with a concentration peak at $10 \mathrm{~nm}$ were identified. For the accumulation-mode, the particle range was between 30 and $560 \mathrm{~nm}$ with the peak at $45 \mathrm{~nm}$.

As shown in Figures 11C and 11D, from the reference SOI the total particles concentration began to increase with the SOI advance. For the $2000 \mathrm{rpm} \_50 \%$ operating point, the total particle concentration increased by $882 \%$ [from $4.84 \times 10^{5} \# / \mathrm{cm}^{3}$ for the reference SOI to $4.76 \times 10^{6} \# / \mathrm{cm}^{3}$ for the most advanced SOI (300 CAD BTDC)]; and for the 3000rpm_50\% operating point this increase was $196 \%$ [from $7.01 \times 10^{5} \mathrm{\#} / \mathrm{cm}^{3}$ for the SOI reference to $2.01 \times 10^{6} \mathrm{\#} / \mathrm{cm}^{3}$ for the most advanced SOI (310 CAD BTDC)]. 
A different behavior was observed when SOI was delayed from the reference SOI (Figures 11C and 11D). For the 2000rpm_50\% operating point, the total particle concentration increased up to $71 \%$ [from $4.84 \times 10^{5} \# / \mathrm{cm}^{3}$ for the reference SOI to $8.29 \times 10^{5} \# / \mathrm{cm}^{3}$ for the most delayed SOI (260 CAD BTDC)]; and for the 3000rpm_50\% operating point this increase was $55 \%$ [from $7.01 \times 10^{5} \mathrm{\#} / \mathrm{cm}^{3}$ for the reference SOI to $1.08 \times 10^{6} \# / \mathrm{cm}^{3}$ for the most delayed SOI (270 CAD BTDC)].
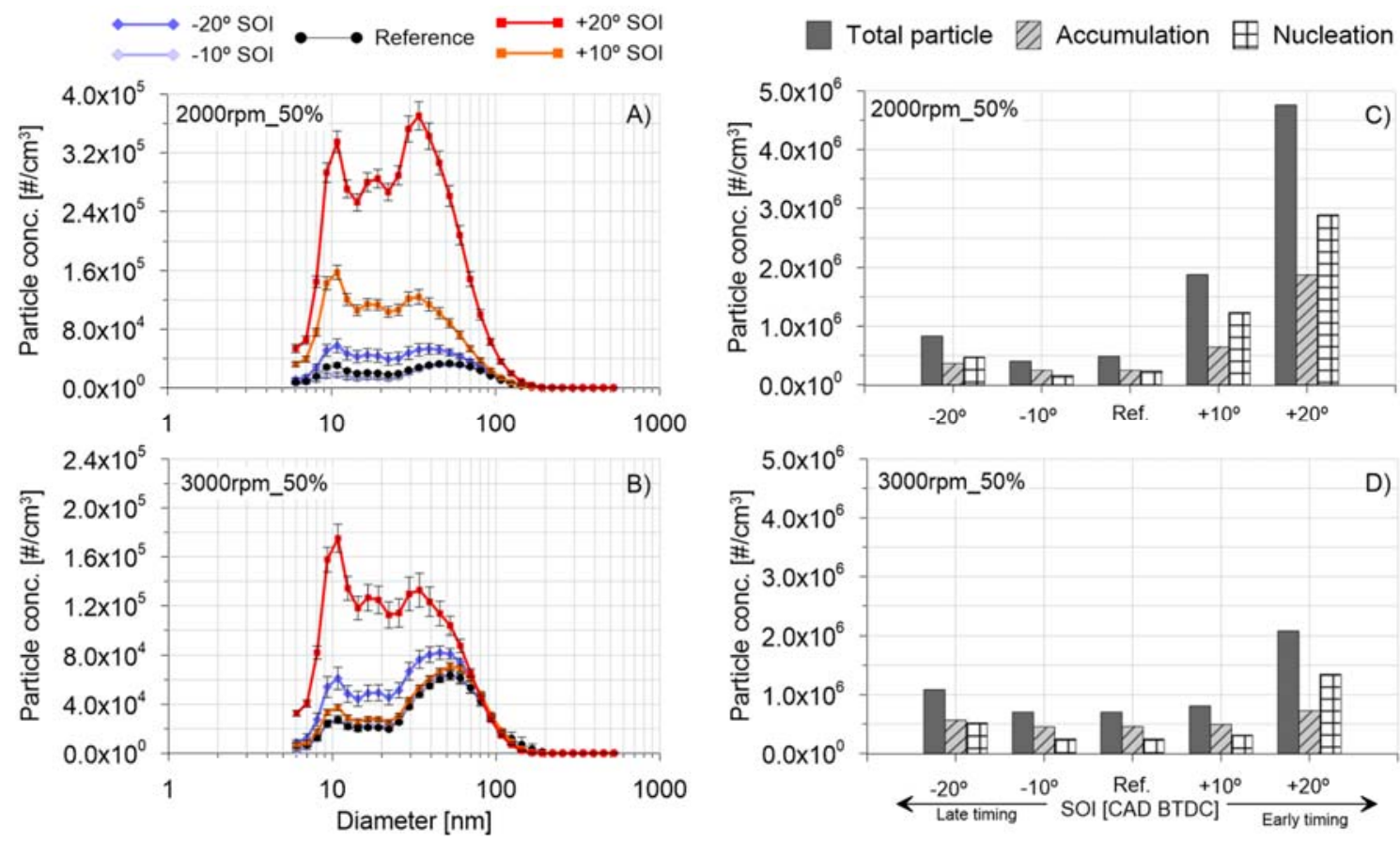

Figure 11. PSD and particle composition analysis for different SOIs at each operating point. (A) PSD at $2000 \mathrm{rpm}$ and 50\% load. (B) PSD at $3000 \mathrm{rpm}$ and 50\% load. (C) Particle composition at $2000 \mathrm{rpm}$ and 50\% load. (D) Particle composition at $3000 \mathrm{rpm}$ and $50 \%$ load.

The results found in terms of $\mathrm{PN}$ emissions can also confirm the analysis performed in the previous section Soot emission analysis. The SOI advance provides a greater quantity of fuel film on the piston surface, and consequently, a larger quantity of PN emissions. On the other hand, around a specific SOI value (in these experiments the value is in accordance with the reference SOI) the SOI delay leads to a shorter time for the AF mixture, which causes an increase in particle emissions. The last factor had less influence on particle emissions and similar results can be found in Price et al. [24] and Wang et al. [22].

As shown in Figures 11C and 11D, for the most advanced SOIs (290 and 300 CAD BTDC for the $2000 \mathrm{rpm} \_50 \%$ operating point and 310 CAD BTDC for the $3000 \mathrm{rpm} \_50 \%$ operating point) it was observed that particles that could form by the pool fire are mostly nucleation-mode. These results fit with the ones presented by Park et al. [67]. Regarding the accumulation-mode particles, a significant 
increase in the measured concentration was observed with the SOI advance from the reference SOI in both operating points. A larger amount of nucleation particles could leads to an increase of surface growing mechanism (coagulation of nuclei) and as a consequence an increase in the formation of accumulation-mode particles $[37,68]$.

The increase in the particle concentration (in both nucleation and accumulation mode) in the most delayed SOI for both operating points is mainly due to a larger quantity of fuel fuel-rich zones (due to in homogeneities in the AF mixture) during the combustion process. Under these conditions, the particles are formed when a partially premixed flame spreads across these locally fuel-rich zones [25]. However a large number of these particles are oxidized immediately, because they are subject to high temperatures at that time, resulting in a reduction of particle emissions [22].

The aforementioned trend shows how the particulate produced is much lower than the particle emissions generated by the pool fire (for most advanced SOIs) when the time available for the $\mathrm{AF}$ mixture is reduced (most delayed SOIs). In the advanced SOIs, particle formation can persist until the end of the combustion cycle where the rate of heat release can decrease significantly, causing a considerable decrease in the subsequent oxidation phase [69-71].

\section{Aftertreatment efficiency}

To evaluate the TWC efficiency, a heated valve system connected to the exhaust gas analyzer (HORIBA MEXA 7100D-EGR) was used to measure raw and tailpipe emissions, as it was previously explained in Test bench facilities and fuel used section and showed in Figure 1. Furthermore, the calculation method has been previously explained in Equation 3.

The TWC efficiency for pollutants abatement depends mainly on three specific exhaust gas parameters [72]: (i) $\mathrm{O}_{2}$ concentration, (ii) $\mathrm{CO}, \mathrm{HC}$ and $\mathrm{CO}_{2}$ concentration and (iii) space velocity (SV).

Although there are many reactions occurring in the catalyst for pollutants abatement, the basic operation of the TWC can be simplified and based on the following reactions [18]:

$$
\begin{aligned}
& \mathrm{C}_{x} \mathrm{H}_{x}+\frac{4 x+\mathrm{Y}}{4} \mathrm{O}_{2} \rightarrow x \mathrm{CO}_{2}+\frac{y}{2} \mathrm{H}_{2} \mathrm{O} \\
& \mathrm{CO}+\frac{1}{2} \mathrm{O}_{2} \rightarrow \mathrm{CO}_{2} \\
& 2 \mathrm{NO}+2 \mathrm{CO} \rightarrow \mathrm{N}_{2}+\mathrm{CO}_{2}
\end{aligned}
$$


As Equation 11 and 12 shown, THC and $\mathrm{CO}$ abatement are mainly related to the $\mathrm{O}_{2}$ content in the exhaust gas.

Figure 12 shows raw $\mathrm{O}_{2}$ emission in the exhaust gas for the different SOIs studied. Based on the results found, $\mathrm{O}_{2}$ concentration increases with the SOI delay in both operating points. The later SOIs provide a reduction of the time for the $\mathrm{AF}$ mixture preparation and consequently increase the heterogeneity mixture. This phenomenon reduces the amount of $\mathrm{O}_{2}$ that it is taking part during the combustion process leaving a higher $\mathrm{O}_{2}$ concentration in the exhaust gas, which is also translated into the CO increase (Figure 9B).

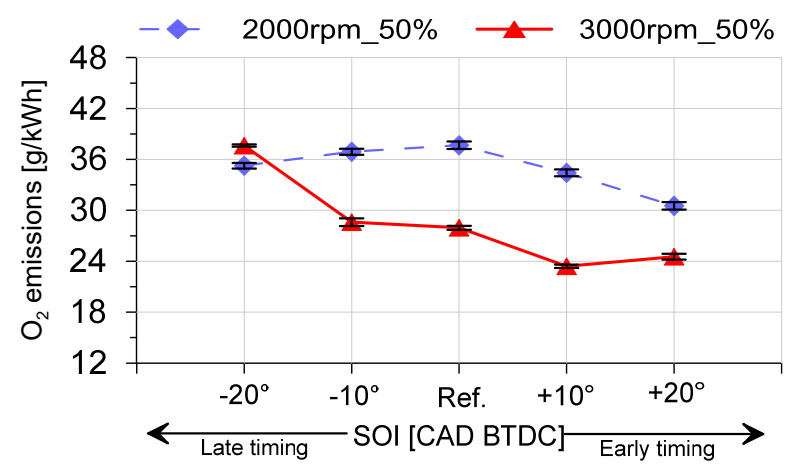

Figure 12. $\mathrm{O}_{2}$ concentrations in exhaust gas for different SOIs at each operating point, upstream the TWC.

Figure 13A shows the TWC efficiency for THC abatement. In both operating points, there were no significant variations in the conversion efficiency for this pollutant. On the one hand although the $\mathrm{O}_{2}$ concentration in the exhaust gas decreased for the most advanced SOIs, the efficiency remained relatively constant with the SOI variation (about $94 \%$ for the $2000 \mathrm{rpm} \_50 \%$ operating point and $85 \%$ for the $3000 \mathrm{rpm} \_50 \%$ operating point).

On the other hand, as shown in Figure 13B, there was an increase in the TWC efficiency for CO abatement with the SOI delay. This is mainly due to the dependence of the $\mathrm{O}_{2}$ concentration for the $\mathrm{CO}$ conversion, as shown in Equation 11. The $\mathrm{O}_{2}$ concentration increased with the SOI delay (Figure. 11), increasing CO efficiency from $85 \%$ to $92 \%$ for the $2000 \mathrm{rpm} \_50 \%$ operating point, and from $69 \%$ to $82 \%$ for the $3000 \mathrm{rpm} \_50 \%$ operating point.

Taking into account the previous results it was shown that the reduction of raw $\mathrm{CO}$ emission was stronger than THC but the efficiency analysis has pointed out that TWC analyzed has a strong THC oxidation reactions interaction with $\mathrm{O} 2$ occur earlier than the $\mathrm{CO}$ reactions. 

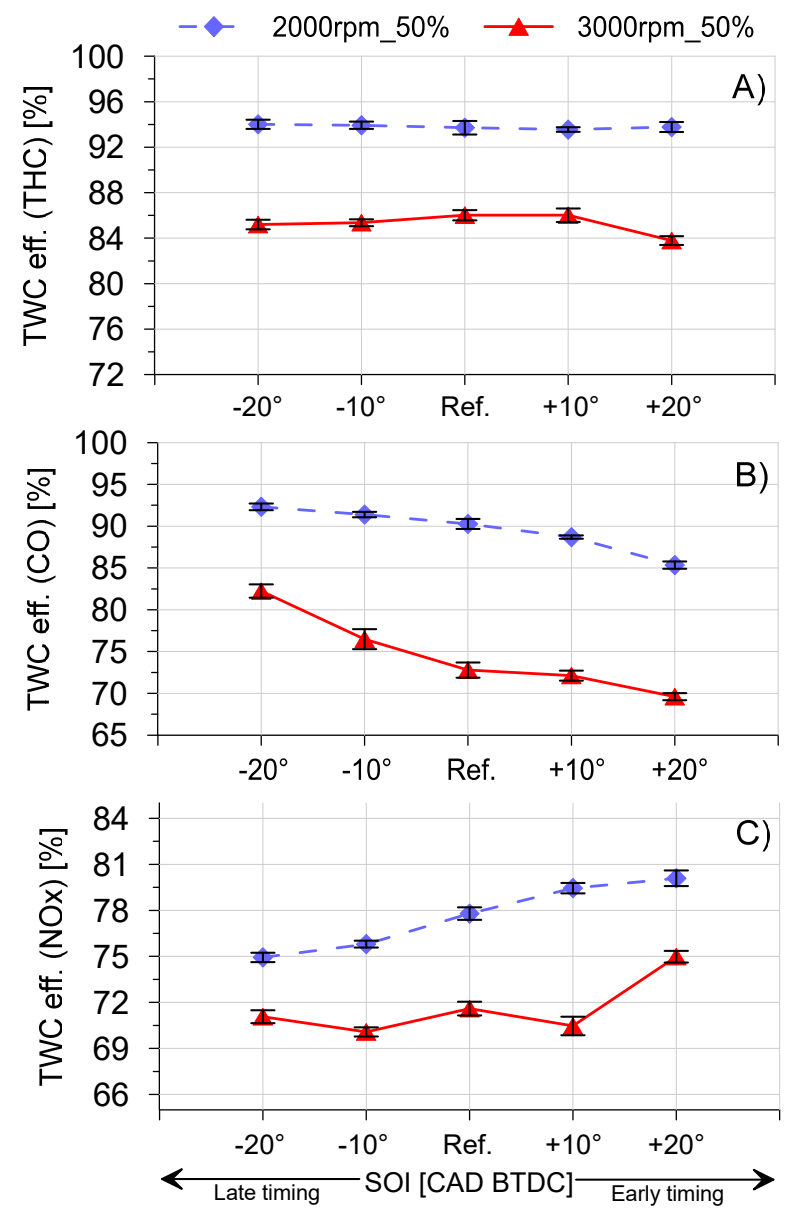

Figure 13. TWC efficiency and tailpipe emissions for different SOIs at each operating point. (A) THC efficiency. (B) CO efficiency. (C) NOx efficiency.

Contrary, a slightly decrease in the TWC efficiency for NOx abatement was observed with the SOI delay, as shown in Figure 12C. Since the reduction reaction for NOx conversion (Equation 13) is highly dependent on the $\mathrm{CO}$ concentration, the increase in the $\mathrm{CO}$ oxidation efficiency provides a decrease in the NOx conversion efficiency (less $\mathrm{CO}$ available for reduction reaction). This behavior was observed mainly in the 2000rpm_50\% operating point, where the NOx efficiency decreased from $80 \%$ for the most advanced SOI to $75 \%$ for the most delayed SOI.

Finally, when comparing the TWC efficiency between the two operating points, an increase in the TWC efficiency was observed when operating in the $2000 \mathrm{rpm} \_50 \%$ operating point. This trend is due to exhaust gas flow decrease of $0.12 \mathrm{~m}^{3} / \mathrm{s}$ for the $3000 \mathrm{rpm} \_50 \%$ to $0.7 \mathrm{~m}^{3} / \mathrm{s}$ for the $2000 \mathrm{rpm} \_50 \%$ operating point, provided by the increase in engine speed. Consequently, in 2000rpm_50\% operating point, the retention time of the exhaust gas is greater (lower SV) facilitating the catalytic conversion and oxidation processes [72,73]. 


\section{Conclusions}

This paper presented an experimental study in a SOI variation in a GTDi engine equipped with LPEGR system. The effects of SOI variation on engine performance, raw gaseous emission, tailpipe soot emission, particle size distribution and TWC efficiency was investigated in two steady-state operating points.

While the influence of SOI variation on PM and NOx emissions have been studied in the past, the present paper makes a significant contribution to the field for its holistic approach. In the literature, several studies have been focused on particle measurement in PFI engines including EGR systems and assessing different EGR ratios [74,75]. Other studies realized with GTDi engines were focused on performance analysis when EGR is added but leaving out particle measurements [76-78] or focusing on particle measurements including different gasoline blends $[79,80]$. Thus, the following section describes the main contributions found of those aspects.

Considering the engine performance, it was possible to observe a slight increase on the BSFC. Advancing this event puts a larger mass of fuel on the piston surface. Thus, a large part of these fuels is not reached by the flame during the combustion process and cannot burn properly, negatively impacting the engine performance.

The main results in terms of gaseous compounds are summarized as follows:

- $\mathrm{CO}$ emissions significantly increased with the SOI delay in both operating points. Result associated with an increase in the charge heterogeneity.

- NOx emissions decreased with the SOI delay. Factor associated with an increase in the deterioration of the combustion process and a decrease on the exhaust temperature.

- $\quad$ THC emissions presented almost non-sensible variations in both operating points.

Focusing on PM emission, the conclusions depicted below have been obtained through this study:

Both soot and PN emissions showed the same trend. The SOI advance can provide an increase in the pool fire intensity and as a consequence a larger quantity of particle emissions. However, around a specific SOI value the SOI delay produces a less time for AF mixture, which causes an increase of PM emissions. The latter factor had less effect on particle emissions. 
Although the European particle measurement program (PMP) method defines that only solid particles above a $23 \mathrm{~nm}$ threshold shall be measured, the results obtained in this work that include measurements of particles with sizes smaller than $23 \mathrm{~nm}$ can be very interesting. In this regard, there is evidence that suggests particulate mass emissions have decreased substantially in recent years with the introduction of new technologies in ICEs [81] but producing an increase up to two orders of magnitude in PN emissions [82]. This is mainly due to the reduced number of solid particles in emissions, leading to a considerable increase in nucleation mode particles. Therefore, it will be almost impossible to rule out the possibility of the measurements of particles with diameters below $23 \mathrm{~nm}$ in future legislation.

Finally, the main conclusions obtained concerning TWC efficiency are listed below:

- $\mathrm{CO}$ oxidation increased with the SOI delay mainly due to the dependence of $\mathrm{O}_{2}$ for $\mathrm{CO}$ conversion. As it was observed, $\mathrm{O}_{2}$ concentrations decreased with the SOI delay.

- NOx conversion decreases with the SOI delay. This behavior can be explained by increase in the CO oxidation efficiency with the SOI delay (less CO available for NOx conversion).

On the one hand, this work has contributed to show how a simple strategy in a GTDi engine can have great influence on pollutants emission levels, a very important aspect nowadays due to the new and demanding emissions regulations. On the other hand, it is important to point out that the inclusion of EGR and timing variation will never be enough to fulfill a change in legislation in terms of emissions. Apart from that, improvements in the combustion chamber design as well as the air-path [83], and the inclusion of a new aftertreatment device (like GPFs -related with PM reduction-) [84] will be needed to approach and meet new legislations.

Taking into account that the SOI variation affects particle emissions, the TWC effect on PM emissions must be analyzed in future works. The TWC catalyst surface is known to be extremely porous and could act as a particle filter. In a study carried out by Mizuno et al. [85] it was found that small pores (20-40 $\mu \mathrm{m}$ in diameter) trapped a significant percentage of PM. Additionally, in the works of Whelan et al. [86,87], it was demonstrated that the catalyst provided a reduction of nucleation-mode particles but an increase in the accumulation-mode particles, a tendency that could be associated with the coagulation of particles. Due to small passage ways in the catalytic converter, the probability of the particles colliding with each other to form particles of larger diameter is much greater. 


\section{Acknowledgements}

The equipment used in this work has been partially supported by FEDER project funds "Dotación de infraestructuras científico técnicas para el Centro Integral de Mejora Energética y Medioambiental de Sistemas de Transporte (CiMeT), (FEDER- ICTS-2012-06)", framed in the operational program of singular scientific and technical infrastructure of the Ministry of Science and Innovation of Spain.

\section{References}

1. Oberdörster G, Oberdörster E, Oberdörster J. "Nanotoxicology: An emerging discipline evolving from studies of ultrafine particles." Environ Health Perspect. 113 (9) :823-39, 2005. doi:10.1289/ehp.7339.

2. Davidson CI, Phalen RF, Solomon PA. "Airborne Particulate Matter and Human Health: A Review." Aerosol Sci Technol. 39 (8) :737-49, 2005. doi:10.1080/02786820500191348.

3. Huang X, Wang Y, Xing Z, Du K. "Emission factors of air pollutants from CNG-gasoline bi-fuel vehicles: Part II. CO, HC and NOx." Sci Total Environ. 565 :698-705, 2016. doi:10.1016/j.scitotenv.2016.05.069.

4. Kemball-Cook S, Yarwood G, Johnson J, Dornblaser B, Estes M. "Evaluating NOx emission inventories for regulatory air quality modeling using satellite and air quality model data." Atmos Environ. $117: 1-8,2015$. doi:10.1016/J.ATMOSENV.2015.07.002.

5. Zong-Jie L, Song L-L, Jing-zhu M, Li Y. "The characteristics changes of pH and EC of atmospheric precipitation and analysis on the source of acid rain in the source area of the Yangtze River from 2010 to 2015." Atmos Environ. 156 :61-9, 2017. doi:10.1016/J.ATMOSENV.2017.02.025.

6. Mamakos A, Martini G, Manfredi U. “Assessment of the legislated particle number measurement procedure for a Euro 5 and a Euro 6 compliant diesel passenger cars under regulated and unregulated conditions." J Aerosol Sci. 55 :31-47, 2013. doi:10.1016/J.JAEROSCI.2012.07.012.

7. Najafi G, Ghobadian B, Tavakoli T, Buttsworth DR, Yusaf TF, Faizollahnejad M. "Performance and exhaust emissions of a gasoline engine with ethanol blended gasoline fuels using artificial neural network.” Appl Energy. 86 (5) :630-9, 2009. doi:10.1016/J.APENERGY.2008.09.017.

8. Banerjee R, Kumar S. "Numerical investigation of stratified air/fuel preparation in a GDI engine." Appl Therm Eng. 104 :414-28, 2016. doi:10.1016/j.applthermaleng.2016.05.050.

9. Bermúdez V, Luján JM, Climent H, Campos D. “Assessment of pollutants emission and aftertreatment efficiency in a GTDi engine including cooled LP-EGR system under different steadystate operating conditions." Appl Energy. 158 :459-73, 2015. doi:10.1016/j.apenergy.2015.08.071.

10. Alkidas AC. "Combustion advancements in gasoline engines." Energy Convers Manag. 48 (11) :2751-61, 2007. doi:10.1016/j.enconman.2007.07.027.

11. Liati A, Schreiber D, Dimopoulos Eggenschwiler P, Arroyo Rojas Dasilva Y, Spiteri AC. "Electron microscopic characterization of soot particulate matter emitted by modern direct injection gasoline engines.” Combust Flame. 166 :307-15, 2016. doi:10.1016/j.combustflame.2016.01.031.

12. Gaddam CK, Vander Wal RL. "Physical and chemical characterization of SIDI engine particulates." Combust Flame. 160 (11):2517-28, 2013. doi:10.1016/j.combustflame.2013.05.025.

13. Cavina N, Businaro A, Moro D, Di Gioia R, Bonandrini G, Papaleo D, et al. "Assessment of the Influence of GDI Injection System Parameters on Soot Emission and Combustion Stability through a Numerical and Experimental Approach.” SAE Int J Engines. 8 (5) :2015-24-2422, 2015. doi:10.4271/2015-24-2422. 
14. Subramaniam MN, Hayes C, Tomazic D, Downey M, Bruestle C. "Pre-Turbo Aftertreatment Position for Large Bore Diesel Engines - Compact \&amp; amp; Cost-Effective Aftertreatment with a Fuel Consumption Advantage." SAE Int J Engines. 4 (1) :2011-01-0299, 2011. doi:10.4271/2011-01-0299.

15. Li J, Mital R. Effect of DPF Design Parameters on Fuel Economy and Thermal Durability. SAE Technical Paper, 2012. doi:10.4271/2012-01-0847.

16. Twigg M V. "Progress and future challenges in controlling automotive exhaust gas emissions." Appl Catal B Environ. 70 (1-4) :2-15, 2007. doi:10.1016/J.APCATB.2006.02.029.

17. Brisiey RJ, Collins NR, French AC, Morris D, O’Sullivan RD, Twigg M V. Advanced PlatinumRhodium Exhaust Catalysts - An Economic Alternative To Palladium-Rhodium. SAE Technical Paper, 2000. doi:10.4271/2000-01-1418.

18. Heck RM, Farrauto RJ. “Automobile exhaust catalysts.” Appl Catal A Gen. 221 (1) :443-57, 2001. doi:10.1016/S0926-860X(01)00818-3.

19. Hasan AO, Abu-jrai A, Turner D, Tsolakis A, Xu HM, Golunski SE, et al. "Control of harmful hydrocarbon species in the exhaust of modern advanced GDI engines." Atmos Environ. 129 :210-7, 2016. doi:10.1016/j.atmosenv.2016.01.033.

20. Poulopoulos SG, Samaras DP, Philippopoulos CJ. "Regulated and speciated hydrocarbon emissions from a catalyst equipped internal combustion engine." Atmos Environ. 35 (26) :4443-50, 2001. doi:10.1016/S1352-2310(01)00231-X.

21. Mueller ME, Blanquart G, Pitsch H. "Hybrid Method of Moments for modeling soot formation and growth.” Combust Flame. 156 (6) :1143-55, 2009. doi:10.1016/j.combustflame.2009.01.025.

22. Wang B, Mosbach S, Schmutzhard S, Shuai S, Huang Y, Kraft M. "Modelling soot formation from wall films in a gasoline direct injection engine using a detailed population balance model." Appl Energy. 163 :154-66, 2016. doi:10.1016/j.apenergy.2015.11.011.

23. Su J, Xu M, Yin P, Gao Y, Hung D. "Particle Number Emissions Reduction Using Multiple Injection Strategies in a Boosted Spark-Ignition Direct-Injection (SIDI) Gasoline Engine." SAE Int J Engines. 8 (1) :2014-01-2845, 2014. doi:10.4271/2014-01-2845.

24. Price P, Twiney B, Stone R, Kar K, Walmsley H. Particulate and Hydrocarbon Emissions from a Spray Guided Direct Injection Spark Ignition Engine with Oxygenate Fuel Blends. SAE Technical Paper, 2007-01-0472; 2007. doi:10.4271/2007-01-0472.

25. Stojkovic BD, Fansler TD, Drake MC, Sick V. "High-speed imaging of $\mathrm{OH}^{*}$ and soot temperature and concentration in a stratified-charge direct-injection gasoline engine." Proc Combust Inst. 30 (2) :2657-65, 2005. doi:10.1016/j.proci.2004.08.021.

26. Berndorfer A, Breuer S, Piock W, Von Bacho P. Diffusion Combustion Phenomena in GDi Engines caused by Injection Process, 2013. doi:10.4271/2013-01-0261.

27. Wei H, Zhu T, Shu G, Tan L, Wang Y. "Gasoline engine exhaust gas recirculation - A review." Appl Energy. 99 :534-44, 2012. doi:10.1016/J.APENERGY.2012.05.011.

28. Hedge M, Weber P, Gingrich J, Alger T, Khalek IA. "Effect of EGR on Particle Emissions from a GDI Engine.” SAE Int J Engines. 4 (1) :2011-01-0636, 2011. doi:10.4271/2011-01-0636.

29. Wheeler J, Polovina D, Ramanathan S, Roth K, Manning D, Stein J. Increasing EGR Tolerance using High Tumble in a Modern GTDI Engine for Improved Low-Speed Performance. SAE Technical Paper, 2013-01-1123; 2013. doi:10.4271/2013-01-1123.

30. Gu X, Huang Z, Cai J, Gong J, Wu X, Lee C. "Emission characteristics of a spark-ignition engine fuelled with gasoline-n-butanol blends in combination with EGR." Fuel. 93 :611-7, 2012. doi:10.1016/J.FUEL.2011.11.040.

31. Galloni E, Fontana G, Palmaccio R. "Effects of exhaust gas recycle in a downsized gasoline engine." Appl Energy. 105 :99-107, 2013. doi:10.1016/J.APENERGY.2012.12.046.

32. Wang C, Xu H, Herreros JM, Wang J, Cracknell R. "Impact of fuel and injection system on particle 
emissions from a GDI engine.” Appl Energy. 132 :178-91, 2014.

doi:10.1016/j.apenergy.2014.06.012.

33. Boccardi S, Catapano F, Costa M, Sementa P, Sorge U, Vaglieco BM. "Optimization of a GDI engine operation in the absence of knocking through numerical 1D and 3D modeling." Adv Eng Softw. 95 :38-50, 2016. doi:10.1016/j.advengsoft.2016.01.023.

34. Costa M, Sorge U, Allocca L. "Increasing energy efficiency of a gasoline direct injection engine through optimal synchronization of single or double injection strategies." Energy Convers Manag. 60 :77-86, 2012. doi:10.1016/j.enconman.2011.12.025.

35. Li Y, Zhao H, Brouzos N, Ma T, Leach B. Effect of Injection Timing on Mixture and CAI Combustion in a GDI Engine with an Air-Assisted Injector. SAE Technical Paper, 2006-01-0206; 2006. doi:10.4271/2006-01-0206.

36. Price P, Stone R, Collier T, Davies M. Particulate Matter and Hydrocarbon Emissions Measurements: Comparing First and Second Generation DISI with PFI in Single Cylinder Optical Engines. SAE Technical Paper, 2006-01-1263; 2006. doi:10.4271/2006-01-1263.

37. Bonatesta F, Chiappetta E, La Rocca A. "Part-load particulate matter from a GDI engine and the connection with combustion characteristics." Appl Energy. 124 :366-76, 2014. doi:10.1016/j.apenergy.2014.03.030.

38. Zheng Z, Tian X, Zhang X. "Effects of split injection proportion and the second injection time on the mixture formation in a GDI engine under catalyst heating mode using stratified charge strategy." Appl Therm Eng. 84 :237-45, 2015. doi:10.1016/J.APPLTHERMALENG.2015.03.041.

39. Roth DB, Keller P, Becker M. Requirements of External EGR Systems for Dual Cam Phaser Turbo GDI Engines. SAE Technical Paper, 2010-01-0588; 2010. doi:10.4271/2010-01-0588.

40. "EUR-Lex - 32016L0802 - EN - EUR-Lex.” EUR-Lex. 2016. http://eur-lex.europa.eu/legalcontent/EN/TXT/?qid=1526295324843\&uri=CELEX:32016L0802.

41. Montajir RM, Kusaka T, Bamba Y, Adachi M. A New Concept for Real-Time Measurement of Particulate Matter (Soot and SOF). SAE Technical Paper, 2005-01-3605; 2005. doi:10.4271/2005-013605.

42. Bermúdez V, Pastor J V, López JJ, Campos D. “Experimental correlations for transient soot measurement in diesel exhaust aerosol with light extinction, electrical mobility and diffusion charger sensor techniques.” Meas Sci Technol. 25 (6) :065204, 2014. doi:10.1088/0957-0233/25/6/065204.

43. Kim D, Gautam M, Gera D. "Parametric studies on the formation of diesel particulate matter via nucleation and coagulation modes." J Aerosol Sci. 33 (12) :1609-21, 2002. doi:10.1016/S00218502(02)00119-2.

44. Desantes JM, Bermúdez V, Molina S, Linares WG. "Methodology for measuring exhaust aerosol size distributions using an engine test under transient operating conditions." Meas Sci Technol. 22 (11) :115101, 2011. doi:10.1088/0957-0233/22/11/115101.

45. Kittelson DB, Watts WF, Johnson JP, Schauer JJ, Lawson DR. "On-road and laboratory evaluation of combustion aerosols—Part 2:: Summary of spark ignition engine results.” J Aerosol Sci. 37 (8) :93149, 2006. doi:10.1016/J.JAEROSCI.2005.08.008.

46. Desantes JM, Bermúdez V, Molina S, Linares WG. "Methodology for measuring exhaust aerosol size distributions using an engine test under transient operating conditions." Meas Sci Technol. 22 (11) :115101, 2011. doi:10.1088/0957-0233/22/11/115101.

47. Seinfeld JH, Pandis S, Noone K. Atmospheric Chemistry and Physics: From Air Pollution to Climate Change. 2nd ed. Hoboken, New Jersey: John Wiley \& Sons Inc; 2006.

48. Kumar P, Fennell P, Britter R. "Effect of wind direction and speed on the dispersion of nucleation and accumulation mode particles in an urban street canyon." Sci Total Environ. 402 (1) :82-94, 2008. doi:10.1016/j.scitotenv.2008.04.032. 
49. Desantes JM, Bermúdez V, Pastor J V., Fuentes E. "Investigation of the Influence of Post-Injection on Diesel Exhaust Aerosol Particle Size Distributions.” Aerosol Sci Technol. 40 (1) :80-96, 2006. doi:10.1080/02786820500466583.

50. Haynes BS, Wagner HG. "Soot formation.” Prog Energy Combust Sci. 7 (4) :229-73, 1981. doi:10.1016/0360-1285(81)90001-0.

51. RÖnkkÖ T, Virtanen A, Kannosto J, Keskinen J, Maija Lappi, Pirjolas L. "Nucleation Mode Particles with a Nonvolatile Core in the Exhaust of a Heavy Duty Diesel Vehicle" 2007. doi:10.1021/ES0705339.

52. Kittelson DB. "Engines and nanoparticles: a review.” J Aerosol Sci. 29 (5) :575-88, 1998. doi:10.1016/S0021-8502(97)10037-4.

53. Lapuerta M, Armas O, Gómez A. "Diesel Particle Size Distribution Estimation from Digital Image Analysis.” Aerosol Sci Technol. 37 (4) :369-81, 2003. doi:10.1080/02786820300970.

54. Luján JM, Climent H, Novella R, Rivas-Perea ME. "Influence of a low pressure EGR loop on a gasoline turbocharged direct injection engine.” Appl Therm Eng. 89 :432-43, 2015. doi:10.1016/j.applthermaleng.2015.06.039.

55. Rodriguez JF, Cheng WK. "Effect of Operation Strategy on First Cycle CO, HC, and PM/PN Emissions in a GDI Engine." SAE Int J Engines. 8 (3) :2015-01-0887, 2015. doi:10.4271/2015-010887.

56. Benajes J, Martín J, Novella R, Thein K. "Understanding the performance of the multiple injection gasoline partially premixed combustion concept implemented in a 2-Stroke high speed direct injection compression ignition engine." Appl Energy. 161 :465-75, 2016. doi:10.1016/J.APENERGY.2015.10.034.

57. Beavis NJ, Ibrahim SS, Malalasekera W. "Impingement characteristics of an early injection gasoline direct injection engine: A numerical study.” Int J Engine Res. 18 (4) :378-93, 2017. doi: $10.1177 / 1468087416663325$.

58. Hennessey R, Fuentes A, Wicker R. Effect of Injection Timing on Piston Surface Fuel Impingement and Vaporization in Direct Injection, Spark Ignition Engines. SAE Technical Paper, 2001. doi:10.4271/2001-01-2025.

59. Arsie I, Di Iorio S, Vaccaro S. "Experimental investigation of the effects of AFR, spark advance and EGR on nanoparticle emissions in a PFI SI engine.” J Aerosol Sci. 64 :1-10, 2013. doi:10.1016/j.jaerosci.2013.05.005.

60. Van Basshuysen R, Spicher U. Gasoline engine with direct injection : processes, systems, development, potential. 1st ed. Weisbaden Germany: Vieweg + Teubner; 2009.

61. Ma F, Wang Y, Wang J, Ding S, Wang Y, Zhao S. "Effects of Combustion Phasing, Combustion Duration, and Their Cyclic Variations on Spark-Ignition (SI) Engine Efficiency." Energy \& Fuels. 22 (5) :3022-8, 2008. doi:10.1021/ef8003027.

62. Murić K, Stenlåås $\mathrm{O}$, Tunestål P. "Zero-dimensional modeling of NOx formation with least squares interpolation.” Int J Engine Res. 15 (8) :944-53, 2014. doi:10.1177/1468087413495843.

63. Ozsezen AN, Canakci M. "Performance and combustion characteristics of alcohol-gasoline blends at wide-open throttle.” Energy. 36 (5) :2747-52, 2011. doi:10.1016/j.energy.2011.02.014.

64. Ozsezen A, Turkcan A, Sayin C, Canakci M. "Comparison of performance and combustion parameters in a heavy-duty diesel engine fueled with iso-butanol/diesel fuel blends." Energy, Explor Exploit. 29 (5) :525-41, 2011. doi:10.1260/0144-5987.29.5.525.

65. Costa M, Marchitto L, Merola SS, Sorge U. "Study of mixture formation and early flame development in a research GDI (gasoline direct injection) engine through numerical simulation and UV-digital imaging." Energy. 77 :88-96, 2014. doi:10.1016/j.energy.2014.04.114.

66. Sjöberg M, Reuss D. "NO x -Reduction by Injection-Timing Retard in a Stratified-Charge DISI 
Engine using Gasoline and E85.” SAE Int J Fuels Lubr. 5 (3) :2012-01-1643, 2012. doi:10.4271/2012-01-1643.

67. Park C, Lee S, Yi U. "Effects of engine operating conditions on particle emissions of lean-burn gasoline direct-injection engine." Energy. 115 :1148-55, 2016. doi:10.1016/j.energy.2016.09.051.

68. Kayes D, Hochgreb S. "Mechanisms of Particulate Matter Formation in Spark-Ignition Engines. 2. Effect of Fuel, Oil, and Catalyst Parameters." Environ Sci Technol. 33 (22) :3968-77, 1999. doi:10.1021/ES981100W.

69. Desantes JM, Bermúdez V, García A, Linares WG. "A Comprehensive Study of Particle Size Distributions with the Use of PostInjection Strategies in DI Diesel Engines." Aerosol Sci Technol. 45 (10) :1161-75, 2011. doi:10.1080/02786826.2011.582898.

70. Bogarra M, Herreros JM, Tsolakis A, Rodríguez-Fernández J, York APE, Millington PJ. "Gasoline direct injection engine soot oxidation: Fundamentals and determination of kinetic parameters." Combust Flame. 190 :177-87, 2018. doi:10.1016/J.COMBUSTFLAME.2017.11.027.

71. Xing J, Shao L, Zheng R, Peng J, Wang W, Guo Q, et al. "Individual particles emitted from gasoline engines: Impact of engine types, engine loads and fuel components." J Clean Prod. 149 :461-71, 2017. doi:10.1016/J.JCLEPRO.2017.02.056.

72. Hasan AO, Abu-Jrai A, Al-Muhtaseb AH, Tsolakis A, Xu H. "HC, CO and NOx emissions reduction efficiency of a prototype catalyst in gasoline bi-mode SI/HCCI engine." J Environ Chem Eng. 4 (2) :2410-6, 2016. doi:10.1016/j.jece.2016.04.015.

73. Shamim T. The Effect of Space Velocity on the Dynamic Characteristics of an Automotive Catalytic Converter. SAE Technical Paper, 2005. doi:10.4271/2005-01-2160.

74. Alger T, Gingrich J, Khalek IA, Mangold B. "The Role of EGR in PM Emissions from Gasoline Engines.” SAE Int J Fuels Lubr. 3 (1) :2010-01-0353, 2010. doi:10.4271/2010-01-0353.

75. Fontana G, Galloni E. "Experimental analysis of a spark-ignition engine using exhaust gas recycle at WOT operation." Appl Energy. 87 (7) :2187-93, 2010. doi:10.1016/J.APENERGY.2009.11.022.

76. Galloni E, Fontana G, Palmaccio R. "Effects of exhaust gas recycle in a downsized gasoline engine." Appl Energy. 105 :99-107, 2013. doi:10.1016/J.APENERGY.2012.12.046.

77. Blank H, Dismon H, Kochs MW, Sanders M, Golden JE. EGR and Air Management for Direct Injection Gasoline Engines. SAE Technical Paper, 2002. doi:10.4271/2002-01-0707.

78. Potteau S, Lutz P, Leroux S, Moroz S, Tomas E. Cooled EGR for a Turbo SI Engine to Reduce Knocking and Fuel Consumption. SAE Technical Paper, 2007. doi:10.4271/2007-01-3978.

79. Gu X, Huang Z, Cai J, Gong J, Wu X, Lee C. "Emission characteristics of a spark-ignition engine fuelled with gasoline-n-butanol blends in combination with EGR." Fuel. 93 :611-7, 2012. doi:10.1016/J.FUEL.2011.11.040.

80. Maricq MM, Szente JJ, Jahr K. "The Impact of Ethanol Fuel Blends on PM Emissions from a LightDuty GDI Vehicle.” Aerosol Sci Technol. 46 (5) :576-83, 2012. doi:10.1080/02786826.2011.648780.

81. Kumar P, Morawska L, Birmili W, Paasonen P, Hu M, Kulmala M, et al. "Ultrafine particles in cities.” Environ Int. 66 :1-10, 2014. doi:10.1016/J.ENVINT.2014.01.013.

82. Kulmala M, Asmi A, Lappalainen HK, Baltensperger U, Brenguier J-L, Facchini MC, et al. "General overview: European Integrated project on Aerosol Cloud Climate and Air Quality interactions (EUCAARI) \&amp;ndash; integrating aerosol research from nano to global scales." Atmos Chem Phys. 11 (24) :13061-143, 2011. doi:10.5194/acp-11-13061-2011.

83. Lee S, Jeon J, Park S. "Optimization of combustion chamber geometry and operating conditions for compression ignition engine fueled with pre-blended gasoline-diesel fuel." Energy Convers Manag. $126: 638-48,2016$. doi:10.1016/J.ENCONMAN.2016.08.046.

84. Van Nieuwstadt M, Ulrey J. Control Strategies for Gasoline Particulate Filters. SAE Technical Paper, 2017. doi:10.4271/2017-01-0931. 
85. Mizuno T, Suzuki J. Development of a New DPNR Catalyst. SAE Technical Paper, 2004. doi:10.4271/2004-01-0578.

86. Whelan I, Samuel S, Hassaneen A. Investigation into the Role of Catalytic Converters on Tailpipe-out Nano-Scale Particulate Matter from Gasoline Direct Injection Engine. SAE Technical Paper, 2010. doi:10.4271/2010-01-1572.

87. Whelan I, Timoney D, Smith W, Samuel S. "The Effect of a Three-Way Catalytic Converter on Particulate Matter from a Gasoline Direct-Injection Engine During Cold-Start." SAE Int J Engines. 6 (2) :2013-01-1305, 2013. doi:10.4271/2013-01-1305.

\section{Contact Information}

Vicente Bermúdez

Tel.: +34963877650

E-mail: bermudez@,mot.upv.es

\section{Abbreviations $\backslash$ Definitions}

$\begin{array}{llll}\text { AF } & \text { air-to-fuel } & \text { PSD } & \text { particle size distribution } \\ \text { ATDC } & \text { after top dead center } & \text { SOI } & \text { start of injection } \\ \text { BTDC } & \text { before top dead center } & \text { SP } & \text { spark-plug } \\ \text { BSFC } & \text { brake specific fuel consumption } & \text { THC } & \text { total unburned hydrocarbons } \\ \text { CAD } & \text { crank angle degree } & \text { TWC } & \text { three-way catalyst } \\ \text { CO } & \text { carbon monoxide } & \text { VO } & \text { valve overlap } \\ \text { COV } & \text { coefficient of variation } & \text { VVT } & \text { variable valve timing } \\ \text { CO2 } & \text { carbon dioxide } & \text { PM } & \text { particulate matter } \\ \text { EGT } & \text { exhaust gas temperature } & \text { PN } & \text { particle number } \\ \text { EGR } & \text { exhaust gas recirculation } & & \\ \text { ECU } & \text { engine control unit } & & \\ \text { GDI } & \text { gasoline direct-injection } & & \\ \text { GTDi } & \text { gasoline turbocharged direct-injection } & & \\ \text { IC } & \text { internal combustion } & & \\ \text { ICE } & \text { internal combustion engines } & & \\ \text { LP-EGR } & \text { low-pressure exhaust gas recirculation } & & \\ \text { NOx } & \text { nitrogen oxides } & & \end{array}$

